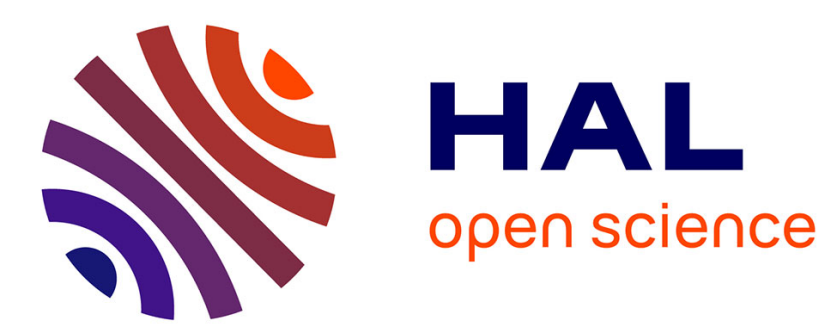

\title{
Sequential Geomagnetic Reversals Recorded in Upper Tortonian Marine Clays in Western Crete (Greece)
} Jean-Pierre Valet, Carlo Laj, Cornelis Langereis, J-Pnau Vxtr Cnlo

\section{To cite this version:}

Jean-Pierre Valet, Carlo Laj, Cornelis Langereis, J-Pnau Vxtr Cnlo. Sequential Geomagnetic Reversals Recorded in Upper Tortonian Marine Clays in Western Crete (Greece). Journal of Geophysical Research, 1988, 93 (B2), pp.1131. 10.1029/JB093iB02p01131 . hal-03551370

\author{
HAL Id: hal-03551370 \\ https://hal.science/hal-03551370
}

Submitted on 1 Feb 2022

HAL is a multi-disciplinary open access archive for the deposit and dissemination of scientific research documents, whether they are published or not. The documents may come from teaching and research institutions in France or abroad, or from public or private research centers.
L'archive ouverte pluridisciplinaire HAL, est destinée au dépôt et à la diffusion de documents scientifiques de niveau recherche, publiés ou non, émanant des établissements d'enseignement et de recherche français ou étrangers, des laboratoires publics ou privés. 


\title{
Sequential Geomagnetic Reversals Recorded in Upper Tortonian Marine Clays in Western Crete (Greece)
}

\author{
JeAN-PIERRE VALET AND CARLo LaJ \\ Centre des Faibles Radioactivites, Laboratoire Mixte CNRS/CEA, Gif-sur-Yvette, France
}

\author{
CORNEIIS G. LANGEREIS
}

Paleomagnetisch Laboratorium, Fort Hoofddijk', Utrecht, Netherlands

\begin{abstract}
We report a very detailed study of four different geomagnetic reversals of upper Tortonian age, recorded in three marine sections in western Crete. Multiple records have been obtained for two of the reversals, and both the directional and the relative field intensity behavior have been studied. The intensity decreases to about $15 \%$ of its pretransitional value in all cases. For the three oldest reversals the sequences of changing field directions of reversals of opposite sense are almost antipodal, suggesting that the process of reversal from either starting polarity stays unchanged for about 1.3 m.y. A change then occurs for the fourth reversal. The occurence of perturbations in the sequence of changing field directions in two records either at the onset or at the end of the reversal are interpreted in terms of a recently suggested mechanism for triggering reversals.
\end{abstract}

\section{INTRODUCTION}

The increasing number of detailed records of geomagnetic reversals published over the last few years has provided important information about some of the principal characteristics of the transitional field, but because of the complexity of the phenomenon, additional data are still required. Many of the studies published so far concern single records of different reversals recorded at different sites, mainly because of the difficulties of finding long continuous temporal sequences. However, important contributions may be expected from a more systematic approach. In order to constrain the harmonic content of the transitional field, multiple records of the same reversal from different and geographically well separated sites are required. In this respect, the several available records of the Matuyama-Brunhes transition obtained from different sites of the northern hemisphere are consistent with the hypothesis that during this reversal the field was dominated by non dipolar axisymmetrical terms [Hoffman, 1983; Williams and Fuller, 1981 ] although detailed records from the southern hemisphere are still needed to distinguish between a quadripolar or an octupolar geometry.

In order to observe the evolution of the transitional field characteristics over a long period of time, successive reversals from the same geographical area are required. Sedimentary sequences can provide the appropriate chronological control, and indeed this type of rocks is specifically well adapted to such studies, in spite of the drawback of the complicated nature of remanence acquisition in sediments. Magnetization of sediments is associated with the continuous process of the sedimentation so that the resulting signal depends on the

Copyright 1988 by the American Geophysical Union.

Paper number 7B3016.

0148-0227/88/007B-3016\$05.00 deposition rate and on the time necessary for the locking-in of the remanence. Depositional detrital magnetization will be present in all subaquaeous deposits, but postdepositional reorientation of the magnetic grains (leading to PDRM) [Irving and Major, 1964; Tucker, 1979] is also likely to occur. Last, the magnetic properties may be affected by authigenic formation of magnetic oxides or hydroxides. The possible influence of these factors must therefore be carefully scrutinized before interpreting any palaeomagnetic result in terms of geomagnetic field variations.

In this paper, we present the results obtained from sequential reversals recorded in three upper Tortonian marine clay sections located in the Kastelli-Kissamos province of western Crete, near the small villages of Potamida and Skouloudhiana (Figure1). Some results obtained from the Potamida 1 and Skouloudhiana sections have previously been reported [Valet and Laj, 1981, 1984; Valet et al., 1983, 1986]. We give here a much more complete and detailed report of these studies, including new results from the section Potamida 4 as well as relative paleointensity data.

\section{Geological SETting and SAMPLING}

The detailed geological and stratigraphic characteristics of the studied sections have already been investigated by a group of Dutch scientists, as part of a general study of upper Miocene sediments in the Mediterranean area, and are reported by Drooger et al. [1979]. The three sections are lithologically very similar composed of 63,55 , and $55 \mathrm{~m}$ respectively of blue-gray, fine-grained, homogeneous clay which forms the upper part of a clastic sedimentary sequence unconformably overlying pre-Neogene rocks. At the top of the Potamida sections, the blue-gray clay is overlain by beige to whitish marls of Messinian age. Intencalated ferruginous levels (Fe I to Fe IV), a few millimeters to $10 \mathrm{~cm}$ thick, provide useful lithological markers. Northwestern Crete is affected by extensional tectonics, and Potamida 1 and 4 are separated by a 


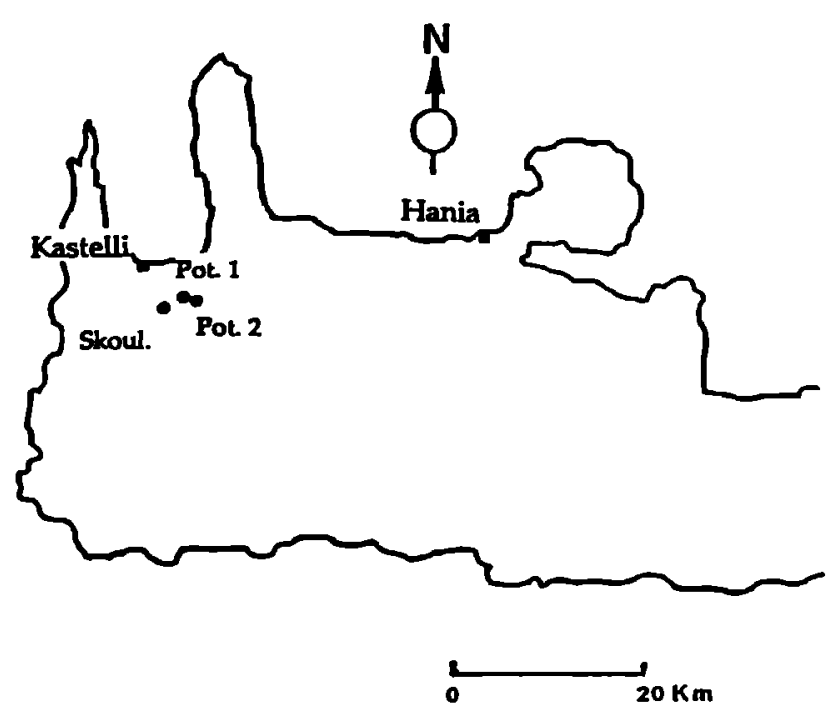

Fig. 1. Schematic map showing the location of the sections Potamida 1, Potamida 4, and Skouloudhiana in western Crete.

large normal fault. A small normal fault is also present in the lower part of Potamida 4, but we did not sample this part of the section. There is no evidence for other large faults or slumped beds. The bedding plane has a constant attitude over the sections: the beds are virtually horizontal at Skouloudhiana and dip $13^{\circ}$ northwest at Potamida 1 and $12^{\circ}$ northeast at Potamida 4. The correlation of the sections, established on the basis of the previous detailed biostratigraphic and magnetostratigraphic results [Langereis, 1984; Langereis et al. , 1983/84], reported in Figure 2 together with the inferred correlation to the Lowrie and Alvarez (1981) polarity scale indicates that the whole stratigraphic sequence covers a time span of more than 2 m.y. Eight successive reversals, numbered from 1 to 8 according to their stratigraphic position, have been identified, with two of them recorded in several sections. The intensity of magnetization in the Skouloudhiana, section was too low to allow a study of reversals 1,3 , and 4 , even with a cryogenic magnetometer, so that only reversals $2,5,6,7$, and 8 could be studied (the names of the reversal records within the sections are given in Figure 2). Sampling spanned a 4-year period. The two lower transition intervals (KP1 01 and KP1 02) in Potamida 1, sampled first, were located using a portable spinner magnetometer [Chiron et al., 1981] and a small field furnace. The other transitions, sampled later, were located using prior magnetostratigraphic results. An electric drill powered by a portable generator was employed for sampling, using a $25-\mathrm{mm}$ amagnetic barrel with a sintered-diamond cutting edge. Water or, less frequently, compressed air was used as a coolant. The great majority of the cores were sampled on surfaces of constant slope to allow good stratigraphic control; places where changes in the color of the sediments indicated possible weathering were avoided. A total of 1858 cores were obtained from 11 distinct transitional zones.

Careful attention was paid to the determination of the precise stratigraphic position of the cores. The position of each core was measured accurately with respect to definite stratigraphic levels previously marked about every $20 \mathrm{~cm}$ on the surface of the section. A detailed description of the method used for this operation is given by Valet [1985]. Comparison of measurements with respect to distinct stratigraphic levels yields identical results within $0.5 \mathrm{~cm}$, and this value was taken as an estimate of the overall accoracy obtained by this method. Precise stratigraphic marks and photographic records have allowed us to correlate the position of the cores drilled during successive field trips with nearly the same accuracy. The cores were cut directly in the field with a diamond saw into samples $22 \mathrm{~mm}$ long, yielding one to five specimens per core. The final stratigraphic position of every sample was calculated in the laboratory using a computer program which took into account the characteristics of the bedding plane, the orientation parameters of the core and its stratigraphic height in the sequence, the position of the sample in the core, and even the width of the diamond saw.

Finally, a continuous section was recovered from each sampling interval. In many cases there were several distinct samples from the same stratigraphic horizon. A $15-\mathrm{cm}$ sampling hiatus in KP1 03 is due to the presence of the ferruginous level Fe IV.

\section{SEDIMENTARY AND Mineralogical Properties}

The main magnetic properties of the sections have already been investigated in the magnetostratigraphic study [Langereis, 1984; Langereis et al., 1983/84]. Further analyses were, however, performed in each transitional interval, paying particular attention to those parameters whose possible changes with stratigraphic height could be an indication of large perturbations in the sedimentary regime.

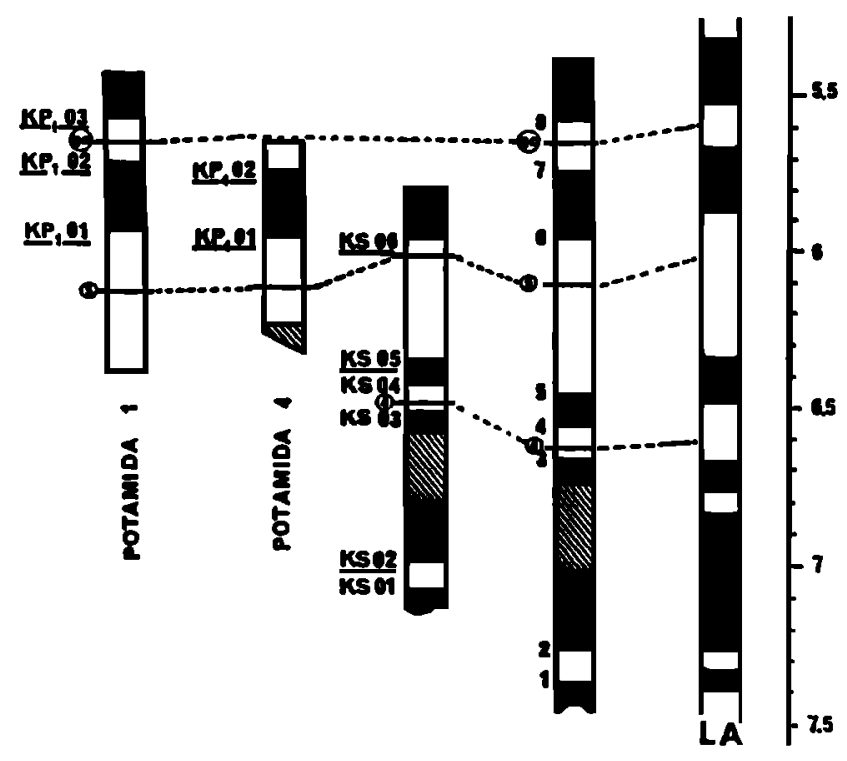

Fig. 2. The stratigraphic columns of the studied sections and their correlation according to the previous magnetostratigraphic results. At the right end the correlation with the Lowrie and Alvarez polarity scale shows that eight successive reversals have been recorded. The names of the individual reversals within each section are indicated and those studied in this paper are underlined; gc, first occurence datum (FOD) of the G. Conomiozea group; 4, last occurence datum of G. Menardii form 4; 5, FOD of G. Menardii form 5. 
TABLE 1. Mean Values of the Relative Abundances of the Major Elements in the Different Sampled Intervals of the Three Sections

\begin{tabular}{|c|c|c|c|c|c|c|c|c|}
\hline & Site & MgO & $\mathrm{Al}_{2} \mathrm{O}_{3}$ & $\mathrm{SiO}_{2}$ & $\mathbf{K}_{2} \mathrm{O}$ & $\mathrm{CaCO}_{3}$ & $\mathrm{TiO}_{2}$ & $\mathrm{Fe}_{2} \mathrm{O}$ \\
\hline \multirow[t]{2}{*}{ Potamida 1} & KP1 02 & $3.29 \pm 0.4$ & $13.20 \pm 0.57$ & $36.88 \pm 1.66$ & $2.79 \pm 0.14$ & $37.7 \pm 2.86$ & $0.54 \pm 0.13$ & $5.44 \pm 0.4$ \\
\hline & KP1 03 & $2.79 \pm 0.2$ & $12.55 \pm 1.24$ & $35.93 \pm 2.02$ & $2.72 \pm 0.16$ & $40.3 \pm 4.0$ & $0.49 \pm 0.09$ & $5.20 \pm 0.6$ \\
\hline \multirow[t]{2}{*}{ Potamida 4} & KP4 01 & $2.92 \pm 0.18$ & $12.50 \pm 0.64$ & $34.90 \pm 0.77$ & $2.61 \pm 0.11$ & $41.2 \pm 1.7$ & $0.56 \pm 0.11$ & $5.20 \pm 0.3$ \\
\hline & KP4 02 & $2.84 \pm 0.11$ & $13.10 \pm 0.11$ & $36.68 \pm 0.65$ & $2.74 \pm 0.09$ & $38.8 \pm 0.07$ & $0.55 \pm 0.07$ & $5.22 \pm 0.17$ \\
\hline \multirow[t]{3}{*}{ Skouloudhiana } & KS $\quad 02$ & $2.50+0.35$ & $14.90 \pm 1.31$ & $38.97 \pm 3.30$ & $2.77 \pm 0.33$ & $34.9 \pm 5.7$ & $0.67 \pm 0.09$ & $5.09 \pm 0.4$ \\
\hline & KS 05 & $2.94 \pm 0.14$ & $11.70 \pm 0.69$ & $34.13 \pm 1.40$ & $2.44 \pm 0.19$ & $43.8 \pm 0.07$ & $0.45 \pm 0.07$ & $4.44 \pm 0.14$ \\
\hline & KS 06 & $3.20 \pm 0.33$ & $18.50 \pm 0.7$ & $64.60 \pm 1.19$ & $3.69 \pm 0.18$ & $37.0 \pm 2.0$ & $0.98 \pm 0.14$ & $8.53 \pm 0.92$ \\
\hline
\end{tabular}

The low value of the stanadard deviation shows that the abundances are very uniform over every studied interval.

Detailed investigations were also performed to check that the magnetic mineralogy was free of authigenic magnetic oxides. All these experiments were performed on series of samples regularly spaced within every sampled interval.

\section{Sedimentary Properties}

$X$ ray diffraction analyses show that the mineralogy is dominated by detrital quartz, clay minerals, and some feldspars in addition to the carbonate fraction. The clay fraction is essentially constituted by illite, chlorite, and kaolinite. Both the nature and relative abundance of these minerals are remarkably constant over every single transitional interval. Parallel microprobe analyses performed on the same samples identified $\mathrm{Ca}, \mathrm{Si}, \mathrm{Al}, \mathrm{Fe}$, and $\mathrm{Mg}$ as the main major elements of the decarbonated fraction, in the order of decreasing abundance. The mean values and their standard deviation (normalized as oxides to $100 \%$ ) are summarized in Table 1 for each transition. As for the clay minerals, the relative abundances of the major elements are remarkably uniform over the individual transitional intervals. All together these results suggest that the relative imputs of the different sedimentary sources did not change significantly.

Measurements of the anisotropy of the magnetic susceptibility show that the magnetic fabric of both the Potamida and Skouloudhiana clays are characterised by an oblate susceptibility ellipsoid with a very weak degree of anisotropy (1.05). The mean axis of minimum susceptibility $\mathrm{K}_{\min }$ is very close to the perpendicular of the bedding plane at Skouloudhiana and $10^{\circ}-15^{\circ}$ away from it at both the Potamida sections (Figure 3). A very weak magnetic lineation trending N-S at Potamida 1 and E-W at Potamida 4 was also observed. On the contrary, no significant lineation was observed at Skouloudhiana, where the $K_{\max }$ axes of individual sarmples are largely scattered in the foliation plane. The magnetic fabric is thus typical of calm water sedimentation with no significant effects arising from bottom currents or postdepositional tectonic events.

\section{Magnetic Mineralogy}

The nature of the magnetic minerals was investigated by combining measurements of stepwise acquisition of isothermal remanent magnetization (IRM) in fields up to 1.5
$T$ and of the low-field susceptibility $\chi$. Typical results, detailed by Valet [1985] show that in the majority of the cases, $85-90 \%$ of the saturation IRM (SIRM) is attained in fields of $0.2 \mathrm{~T}$, indicating that magnetite is the dominan magnetic mineral in these clays. In some cases, however, the SIRM is attained at higher fields, indicating that a second mineral with higher coercivity is also present. These results have been confirmed by stepwise alternating field (af) and thermal demagnetization of the SIRM showing that the median destructive field of the SIRM is close to $25 \mathrm{mT}$ and that over $90-95 \%$ is lost after heating at $580^{\circ} \mathrm{C}$. The complete removal by thermal demagnetization is obtained between $580^{\circ} \mathrm{C}$ and $630^{\circ} \mathrm{C}$. As an exception, only $70 \%$ of the SIRM is attained at $0.2 \mathrm{~T}$ and $90 \%$ at $0.6 \mathrm{~T}$ in samples located near the ferruginous level Fe IV in KP1 03. Formation of authigenic minerals is thus likely to have occurred near this level.

Both the magnetic susceptibility and the SIRM are dependent on the amount and nature of the magnetic minerals. Changes with stratigraphic height of these two parameters (Figure 4) do not, however, exceed a factor of 3 and provide an additional indication that the sedimentary conditions did not significantly change during the time span of the studied reversals [Lowrie and Heller, 1982]. Moreover, because, for a given mineral, the values of $\chi$ and the SIRM are determined mainly by grains of different size, one may expect large changes in the $\chi / S I R M$ ratio if the grain size distribution changes. The plots reported in Figure 4 show that the $\chi / S I R M$ ratios are remarkably constant over the sampled intervals, with mean values between 4 and $8 \times 10^{-5} \mathrm{~m} / \mathrm{A}$ depending on the interval, all of which are typical of fine-grained magnetite. The slightly higher ratios obtained for KS 02 and KS 05, coupled with a decrease observed for each of the two parameters, may indicate coarser magnetic grains, but the differences are inconsistent with any dramatic change. The changes around the ferrugineous level are, on the contrary, more likely to be an effect of changes in the nature of the magnetic minerals and confirm a significant decrease of the amount of fine-grained magnetite.

Banerjee et al. [1981] and King et al. [1982] have shown that relative size changes and the approximate size range of magnetite grains can be evaluated by plotting the values of $\boldsymbol{X}$ (ARM) (anhysteretic remanent magnetization acquired in a $100 \mathrm{mT}$ af and $1 \mathrm{mT}$ direct fields), as a function of $\chi$. For a sedimentary column in which the main magnetic mineral is 

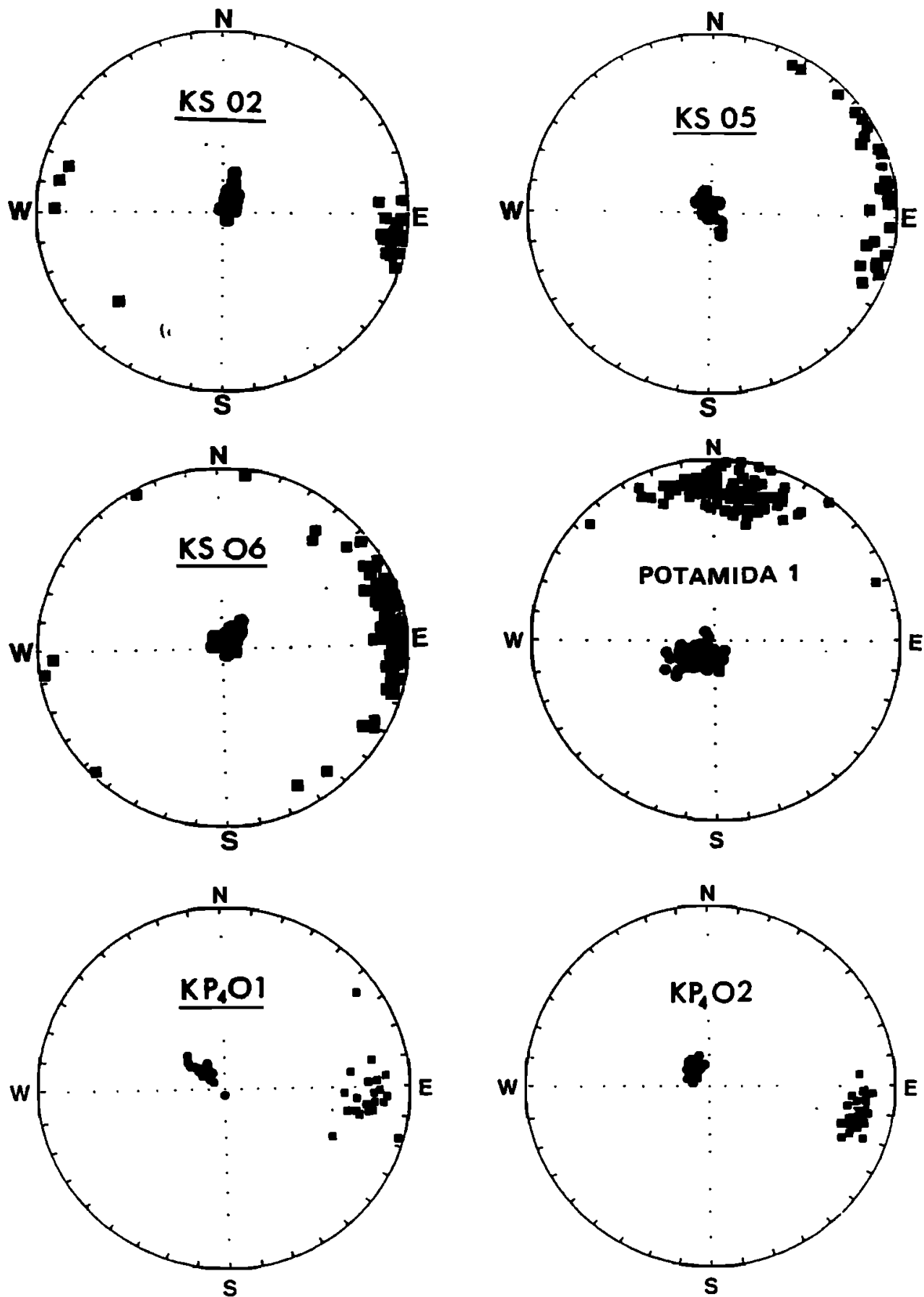

Fig. 3. The anisotropy of the magnetic susceptibility in the three sections is typically sedimentary, with the Kmin axes perfectly close to the pole to the bedding plane at both Potamida sections and only slightly away from it in Skouloudhiana. The weak magnetic lineation observed at Potamida is absent at Skouloudhiana, where the Kmax axes are largely scattered in the bedding plane.

magnetite, changes in the average grain size will result in clearly visible changes in the slope of a regression line fitted to the individual values.

The plots corresponding to the transitional zones KP4 01, $\mathrm{KP1} 02$, KS 02, and KS 05, shown in figure 5, indicate that the magnetite from the KP4 01 and KP1 02 zones is characterized by very uniform grain sizes smaller than 0.1 $\mu \mathrm{m}$. This result agrees with the very fine grain sizes $(0.05-0.2 \mu \mathrm{m})$ of the magnetic mineral extract obtained by
Chang and Kirschvink [1985] from the Potamida and Skouloudhiana clays. The plots relative to KS 02 and KS 05 are consistent with coarser grain sizes (between 0.2 and 5 $\mu \mathrm{m})$, specifically in the upper part of the samplings.

When considered all together, these results indicate that, except for the very localized ferrigineous level, the magnetic mineralogy of the Potamida and Skouloudhiana clays is dominated by fine-grained magnetite. They also provide good evidence of a uniform and undisturbed sedimentary 

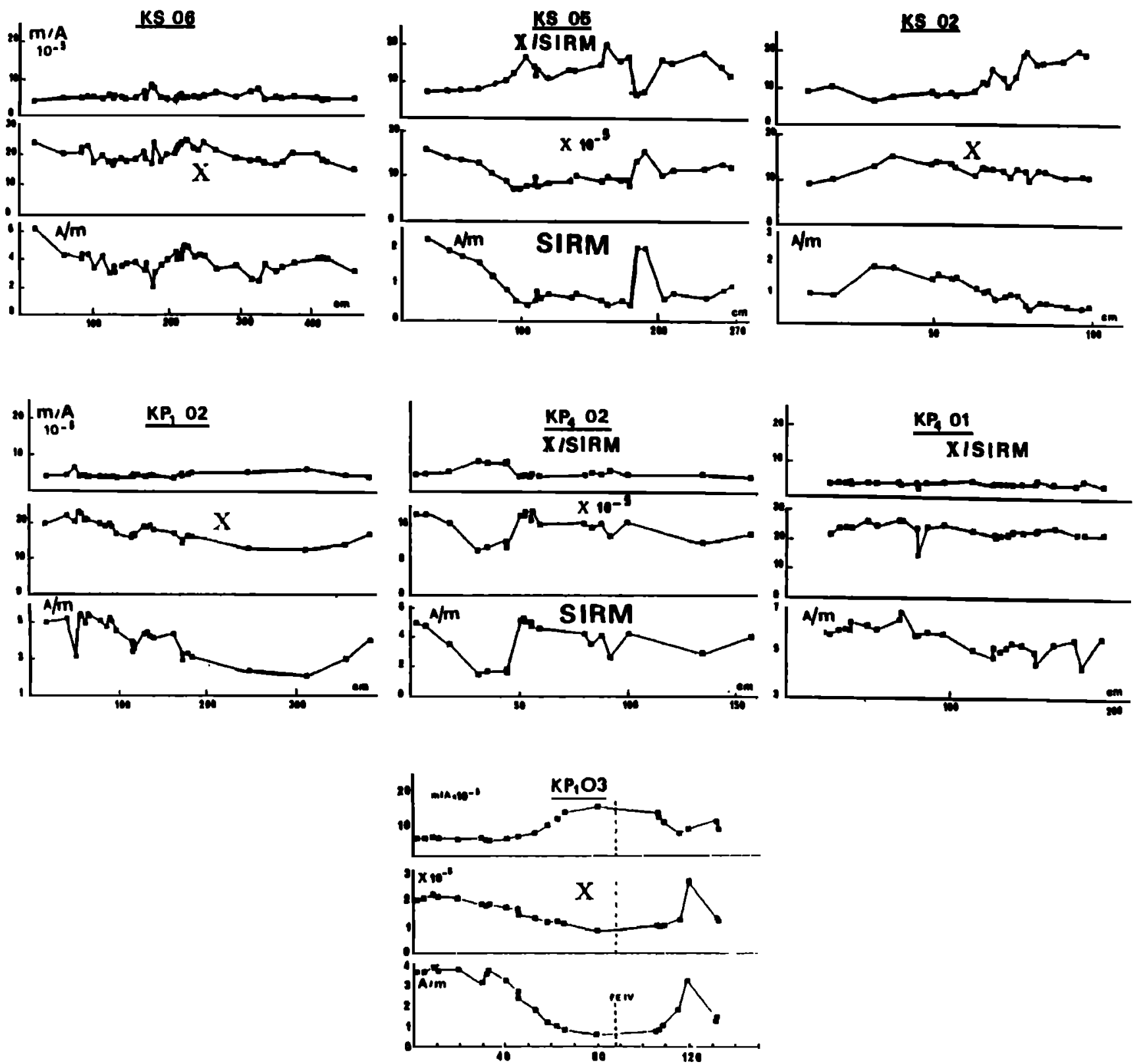

Fig. 4. The plots of the low-field magnetic susceptibility $\chi$ and of the saturation remanent magnetization do not change significantly over the different sampled zones. The ratio $\chi /$ SIRM is remarkably constant over the sampled zones with values between 4 and $8 \times 10^{-5} \mathrm{~m} / \mathrm{A}$, which are quite typical of fine-grained magnetite.

environment, so that one may reasonably assume that no large changes of the sedimentation rate occurred over the time interval of each reversal.

\section{The Stable Pal bomagnetic Directions}

\section{Experimental Data}

The measurements have been made partly with a spinner and partly with a cryogenic magnetometer. The natural remanent magnetization (NRM) ranges between 0.5 and $15 x$ isolated the same stable paleomagnetic direction, but the thermal treatment was preferred because of the overall better consistency of the results obtained with this method. Each sample has been demagnetized with steps of $30^{\circ} \mathrm{C}-50^{\circ} \mathrm{C}$ from room temperature to the highest possible temperature at which the measurement could still be done with the required accuracy. Depending on the samples, this temperature ranges between $450^{\circ} \mathrm{C}$ and $580^{\circ} \mathrm{C}$. Measurements of the low-field magnetic susceptibility at each step of the thermal demagnetization and some Curie balance experiments were used to check the stability of the magnetic minerals upon heating. Only moderate changes of $\chi$ by a factor of 2 to 4 , occurred between $400^{\circ} \mathrm{C}$ and $500^{\circ} \mathrm{C}$. The saturation magnetization increased by a factor of about 2 in the same range of temperatures and decreased abruptly after $500^{\circ} \mathrm{C}$ before 

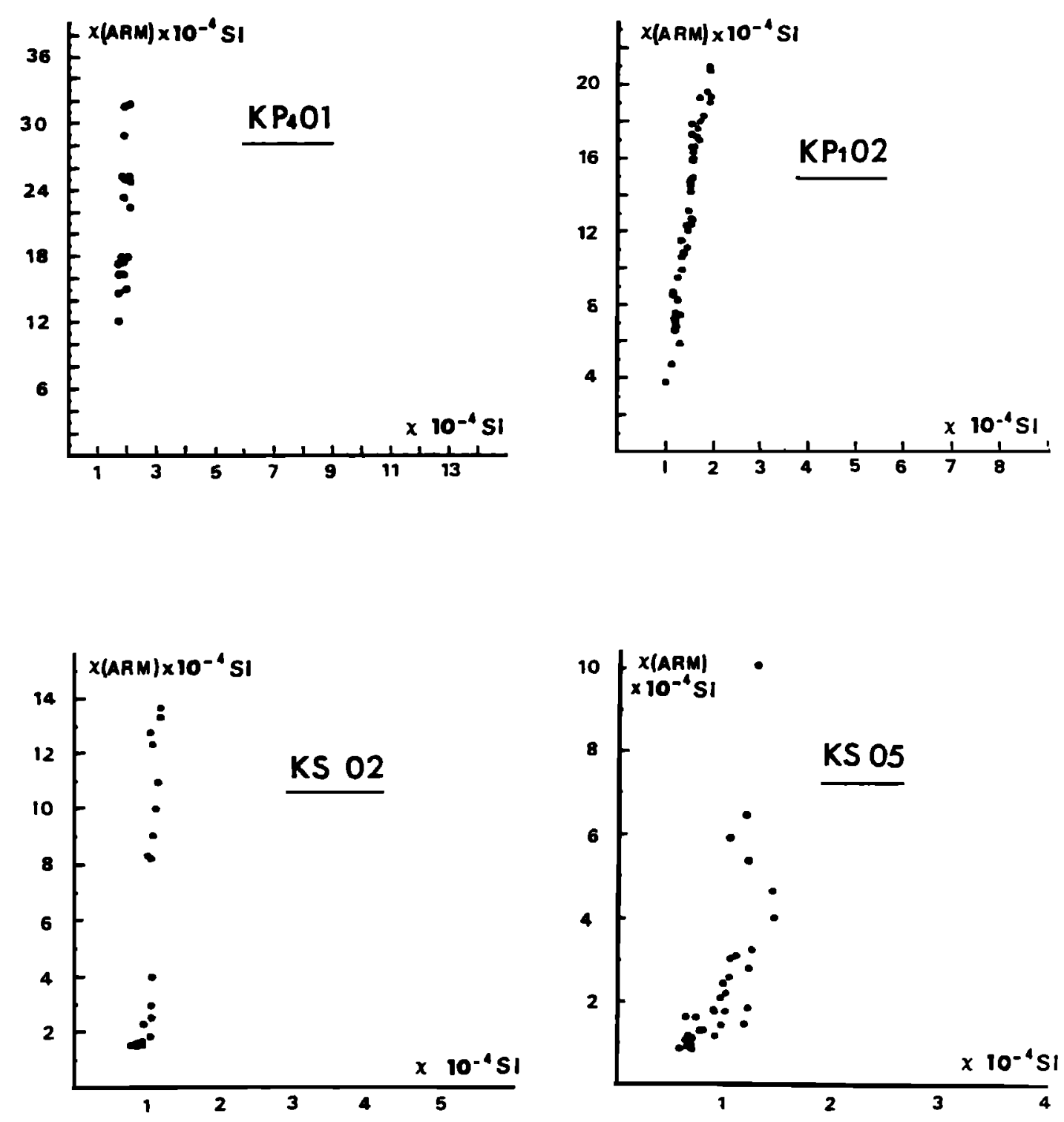

Fig. 5. Plots of the anhysteretic susceptibility $\chi$ (ARM) as a function of the low-field susceptibility for samples from the indicated transitional zones. The different points cluster about a well-defined regression line, indicating that the magnetite is characterized by a very uniform grain size.

disappearing at $580^{\circ} \mathrm{C}$, the Curie point of magnetite. The same experiments performed in vacuum have shown that the mineralogical phase produced between $400^{\circ} \mathrm{C}$ and $500^{\circ} \mathrm{C}$ may be due to the reduction of the iron sulfides into magnetite. This phase did not affect the directions of magnetization since thermal demagnetization occurred in zero field. These experiments thus indicate that only moderate mineralogical changes occur during the thermal treatment.

The components of magnetization were determined from the demagnetization diagrams, some of which are shown in Figure 6. In most cases, three distinct components of magnetization are present. The first one, clearly apparent on diagrams relative to transitional samples because of the weak intensity of the stable component, is completely removed after heating at $100^{\circ} \mathrm{C}-150^{\circ} \mathrm{C}$ and has probably been acquired in the laboratory. The second component, also clearly observed on reversed and intermediate polarity samples, is more or less directed along the present geomagnetic field and is thus probably of viscous origin. About $80 \%$ of this second component are destroyed by heating at $200^{\circ} \mathrm{C}$. In the majority of the samples complete removal is attained at $300^{\circ} \mathrm{C}$, but in some isolated cases $400^{\circ} \mathrm{C}-500^{\circ} \mathrm{C}$ is required. Finally, the third component, which we consider primary, is stable up to $580^{\circ} \mathrm{C}$. The small residual magnetization sometimes present after $580^{\circ} \mathrm{C}$ is probably due to haematite.

The final palaeomagnetic directions were determined with good accuracy by hand-fitting a straight line through at least the last four to five points. Overall, only about $7 \%$ of the diagrams did not allow a precise determination. However, for the most weakly magnetized zones KS 05 and KP1 03 the fraction of rejected diagrams is of the order of $30 \%$.

\section{Results}

The records of the declination, inclination, and intensity (after $300^{\circ} \mathrm{C}$ ) as a function of stratigraphic height have been 

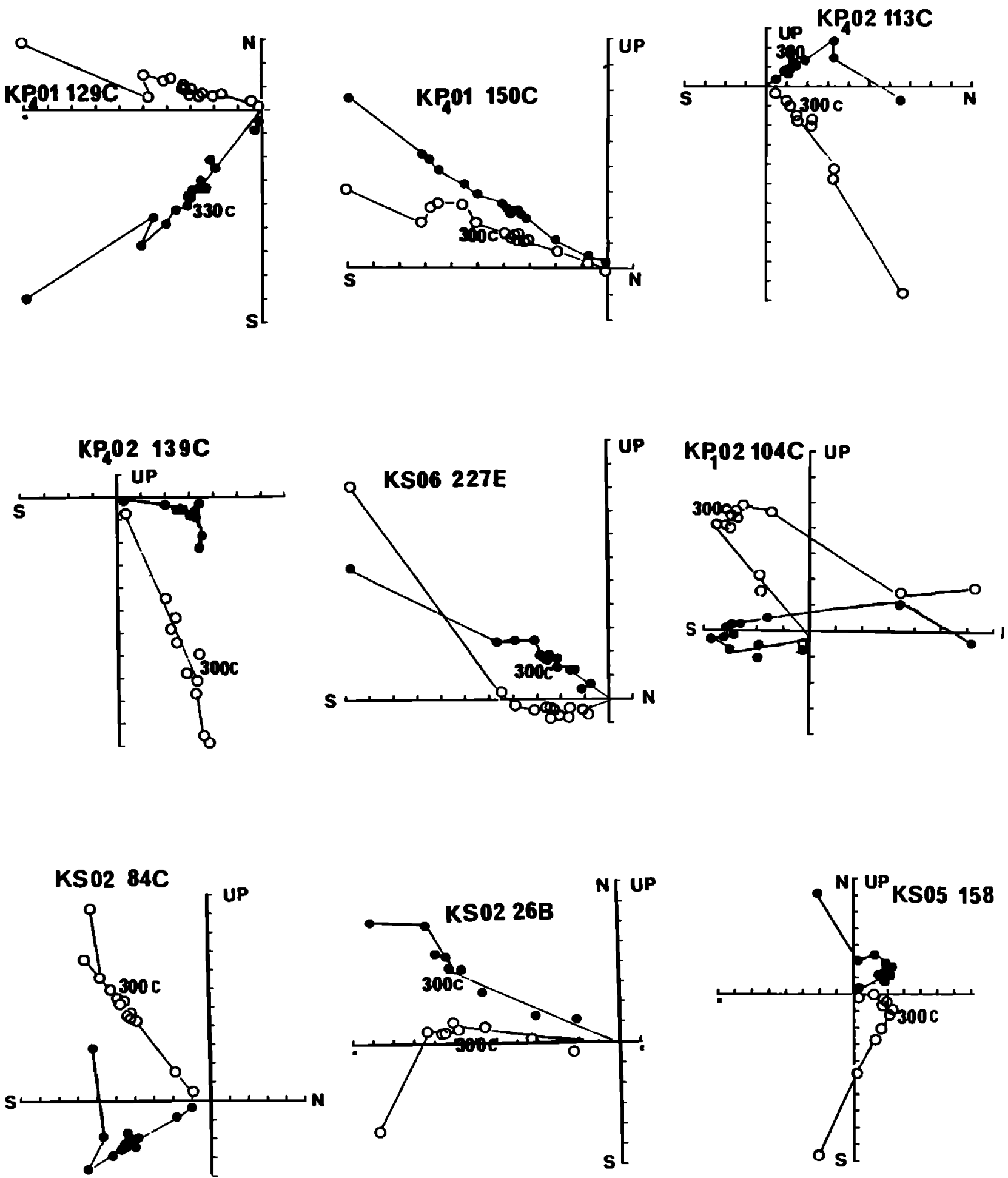

Fig. 6. Thermal demagnetization diagrams corresponding mostly to transitional samples. In all cases the direction of the stable component of magnetization has been determined with a good accuracy.

obtained for every transition. Those relative to reversals KP4 01 and KP4 02 are reported in Figure 7 as an example. In Figure 7 each point corresponds to the result obtained on a single sample except when the stratigraphic height between two successive samples was less than $0.5 \mathrm{~cm}$, which is the limit of accuracy on the stratigraphic position. In these cases, the average direction of the samples has been reported. In
01 and KP4 02 are reported in Figure 7 as an example. In Figure 7 each point corresponds to the result obtained on a single sample except when the stratigraphic height between two successive samples was less than $0.5 \mathrm{~cm}$, which is the limit of accuracy on the stratigraphic position. In these cases, the average direction of the samples has been reported. In every case the sequences of changing field direction for 


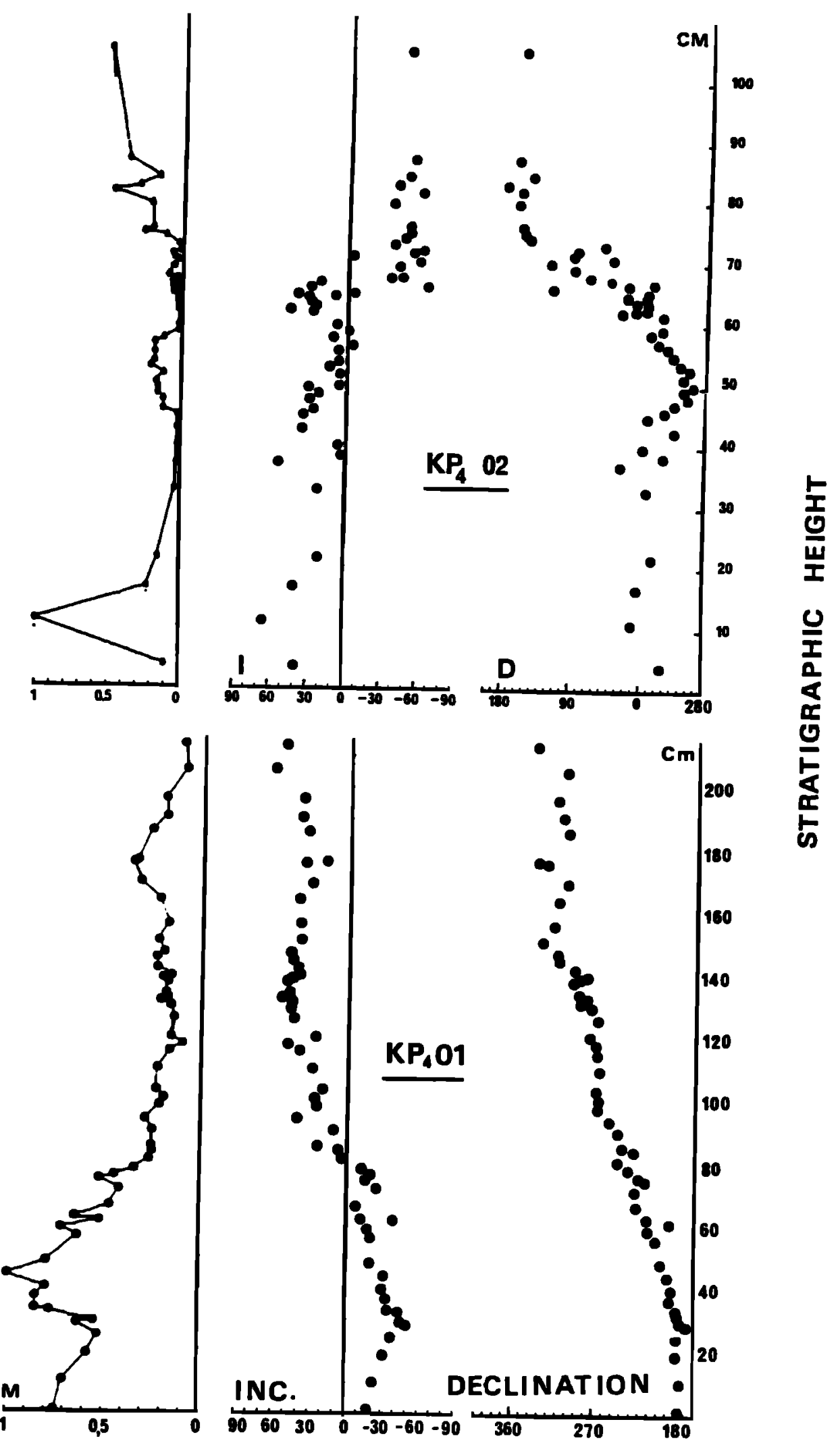

Fig. 7. Records of the declination and the inclination obtained after thermal demagnetization for the transitions studied in the Potamida 4 section. The variations of the magnetization intensity after the $300^{\circ} \mathrm{C}$ step is also reported (normalized to unity outside the transition zone). 


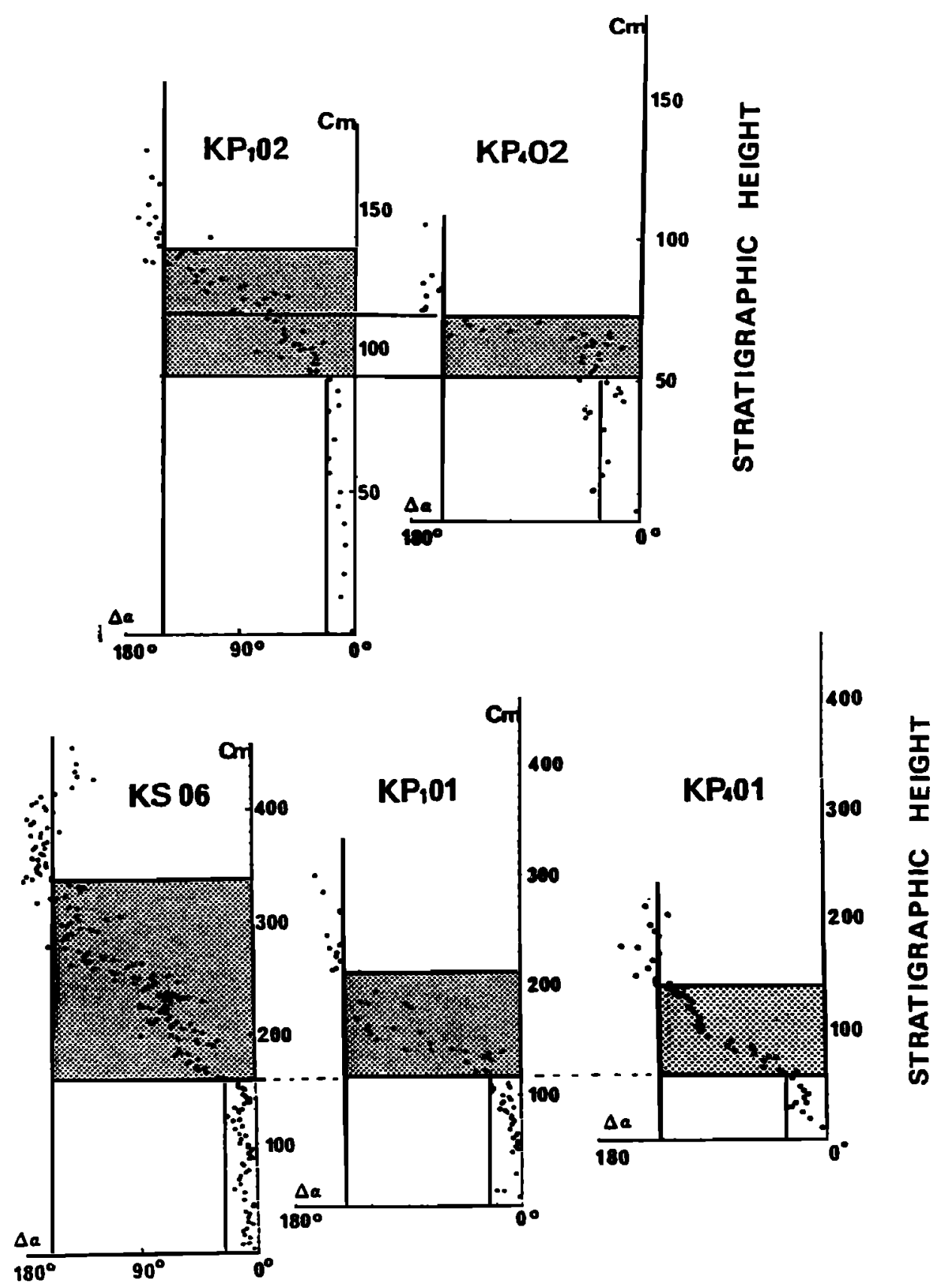

Fig. 8. Stratigraphic height of the transitional zones obtained for the multiple records of reversals 6 and 7. The differences in the length of the transitional zones observed in the different sections show that the sedimentation rate has varied independently on each section on a time scale of the order of $10^{4}$ years.

reversals of opposite sense are almost antipodal, with a westerly declination associated with $\mathbf{R}-\mathbf{N}$ transitions and an easterly one with the $N-R$ ones. The mean value of the inclination obtained from samples well outside the transition zones is about $10^{\circ}$ shallower than expected on the basis of a geocentered dipole field. This is a general characteristic not only of Potamida and Skoulhoudiana but also of all the sedimentary sequences of similar nature over the entire Hellenic sedimentary arc, most probably related to compaction of the sediments [Laj et al., 1982]. A mathematical correction of this error, e.g. using a formula such as $\tan I^{\prime}=f \tan I$, [King, 1955], does not significantly change the data so that we prefer to report and discuss the results free of any artificial treatment.

The durations of the reversals can, in principle, be obtained from the thickness of the transitional intervals, assuming regular and uniform sedimentation rate. The boundaries of the transition zones themselves may be defined in several ways [Clement and Kent, 1984]. We have checked that the stratigraphic boundaries determined using two different methods did not differ significantly. Indeed, virtually identical results are obtained when the field is considered transitional either (1) as soon as its angular deviation from its pretransitional value exceeds twice the value of the mean amplitude of the pretransitional field variations, or (2) when the scatter on the virtual geomagnetic poles (VGPs) exceeds the circular standard deviation (csd) of the reverse and normal polarity zones.

An intriguing feature which is apparent from the results of Figure 8 is that the range of $\Delta \alpha$ values associated with the 

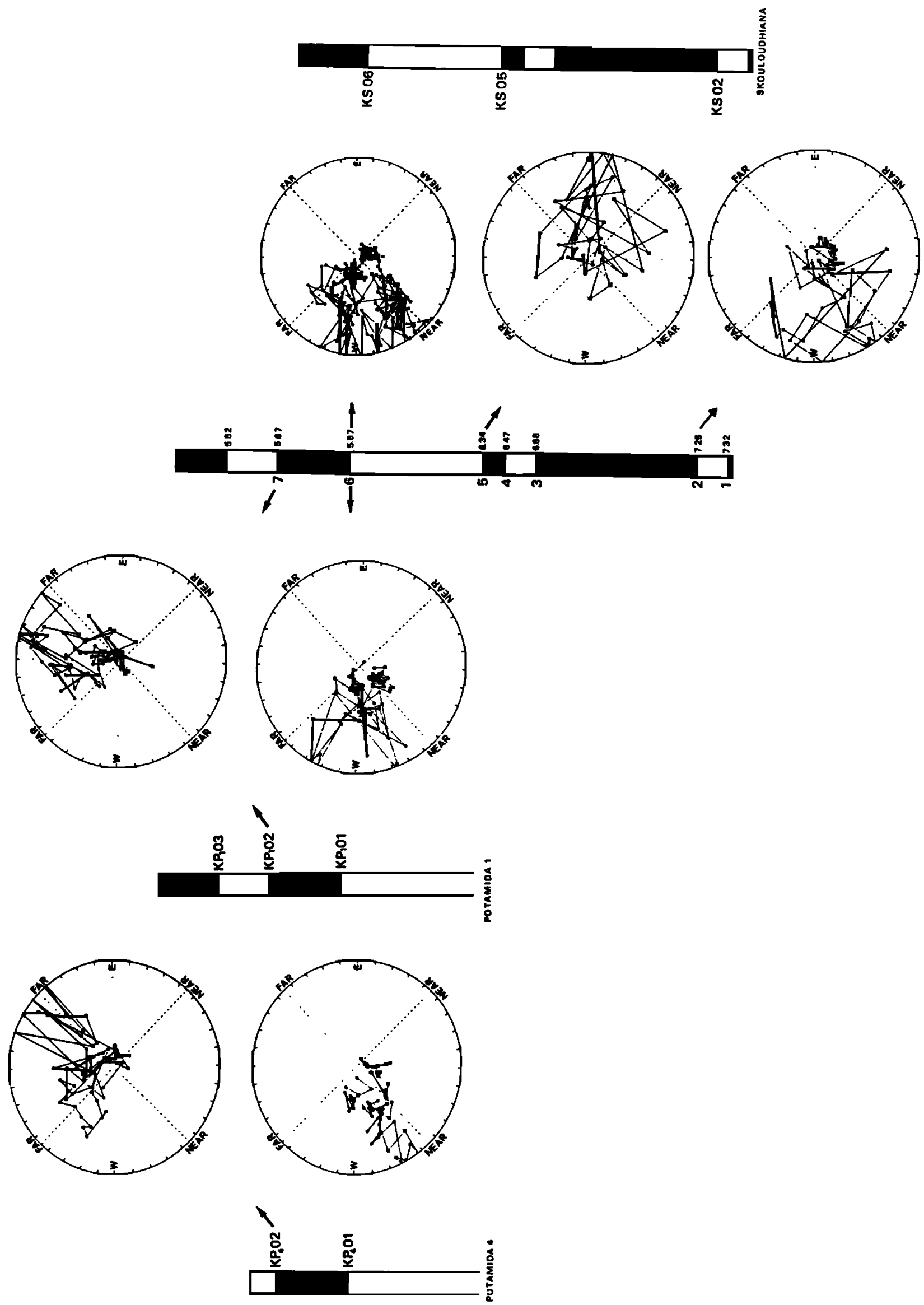
transitional directions may differ for the different records of the same reversal. We think that this feature is the consequence of the inclination error which has different values in the different sections. In any case, this error does not affect the striking feature appearing from Figure 8, namely, the fact that the length of the KS 06 transition is twice that of the two other records of this transition from Potamida 1 and Potamida 4. The same remark holds also for the record of transition 7 from Potamida 1 by comparison to the one from Potamida 4. These results disagree with the fact that the lengths of the polarity intervals deduced from the magnetostratigraphic results are the same on the three sections. Such differences can only be explained by assuming that the sedimentation rate varied independently on each section on a time scale shorter than the durations of the polarity chrons. Therefore no estimation of the duration of a reversal can be given to better than a factor of 2 or 3 . The values obtained using the average sedimentation rate of $4 \mathrm{~cm}$ per 1000 years determined from the magnetostratigraphic results [Langereis, 1984] vary between 5,000 and 20,000 years and are thus of the same order of magnitude as the values reported in the literature [Hoffman, 1983; Jacobs, 1984].

\section{INTERPRETATION OF THE RESULTS IN TERMS OF TRANSITIONAL FIELDS}

From the paleomagnetic directions obtained after demagnetization, we have calculated both the successive rotated directions $D^{\prime}, I^{\prime}$ (Figure 9) [Hoffman, 1984] and the corresponding VGP paths (Figure 10). In Figure 10, we have reported the usual north VGPs for the R-N transitions and the south VGPs for the N-R ones to allow a direct comparison between records of reversals of opposite senses as discussed below.

The records are characterized by a large number of rotated directions more than $30^{\circ}$ away from the axial dipole direction or by the corresponding number of VGPs at intermediate latitudes $\left(<60^{\circ}\right)$, so that they are easily classified in category "A", as defined by Fuller et al. [1979].

To interpret these results in terms of transitional reversing fields, however, it is necessary to first establish that the relatively slowly deposited sediments from Potamida and Skouloudhiana are suitable for recording fast changing field directions.

\section{Directional Fluctuations and Time Resolution of the Records}

Experiments on laboratory-deposited sediments [ $L p v$ lie, 1976; Verosub, 1977; Tucker, 1980, 1983; Katsuma and Sasajima, 1983] have shown that postdepositional detrital magnetization (PDRM) may introduce a smoothing in the recording of the magnetic signal. The extent of smoothing is controlled by many parameters, such as the nature of the sediment and its deposition rate. Following Salloway [1983], we developed elsewhere [Valet, 1985] a simple model simulating a postdepositional remanence acquisition for a sediment deposited during a reversal. The main conclusion stemming from this model is that some features inherent to the records themselves can be used to estimate the extent of
PDRM. In particular, no fluctuation of direction or of intensity can be introduced by a long locking-in time of the remanence. Conversely, in the absence of perturbations related to the magnetization process or to the measurements, any fine-scale variation in a record is representative of a real geomagnetic field variation and can be used to estimate roughly the amount of smoothing. A similar conclusion has recently been reached by Hoffman and Slade [1986].

All the Cretan records are characterized by rapid directional changes clearly apparent in Figure 11, where the angular changes $\Delta \alpha_{i}$ between two successive vectors are plotted as a function of the stratigraphic height.

A striking characteristic of these plots is the significant increase of the amplitude of $\Delta \alpha_{i}$ associated with the directional changes during the reversals. This significant increase could have been equally displayed using the records of the variations of the declination $\left(\Delta D_{i}\right)$ and of the inclination $\left(\Delta J_{i}\right)$. We have used the $\Delta \alpha$ representation because it gives, in our opinion, a better estimate of the relative variations of the full vector. The origin of these fluctuations needs, however, to be thoroughly scrutinized before any interpretation in terms of fluctuations of the transitional geomagnetic field can be given. Different spurious factors such as : (1) errors in the stratigraphic position of the samples; (2) instrumental errors in the measurement of the very weak magnetizations and (3) overprints acquired in relatively strong nontransitional fields, which can produce large spurious directions when vectorially added to primary directions acquired in weak transition fields [Merrill and McElhinny, 1983], could indeed result in an increased directional scatter during the transitions.

A discussion about the possible influence of these factors has already been given for the very detailed record of the KS 06 transition at Skouloudhiana. In this record, several fluctuations, defined by several successive points, exceed $40^{\circ}$. Neither the small $(0.5 \mathrm{~cm})$ maximum stratigraphic error nor the instrumental error (of the order of $5^{\circ}$ for the weakest samples) can account for such large fluctuations.

The third point is more delicate to discuss. Indeed, when all the records are considered, it appears that the mean amplitude of the fluctuations is larger for the records corresponding to a weak magnetization of the transitional zone. Obviously, the interpretation of rapid fluctations is more delicate for weakly magnetized records. It is, however, noteworthy that for a given magnetization, much larger variations are associated with transitional rather than with nontransitional directions; for instance, the amplitude of fluctuations before transition KP1 02 is smaller than during transition KS 06, while the magnetization of the two intervals is identical. Moreover, it is also striking that the fluctuations undergo a sudden increase at the onset of the directional changes and thus do not appear associated to the much slower decrease of the magnetization which occurs before them (see discussion below). It may also be noted that astonishingly fast directional fluctuations of the transitional field have been reported at the Steens Mountain [Prévot et al., 1985 a,b]. Such fluctuations would be recorded at Skouloudhiana over a very short stratigraphic interval, involving one or two samples at most. Thus the apparent lack of coherence of the fluctuations observed at some levels is not in itself a proof of random noise. Finally, if the 


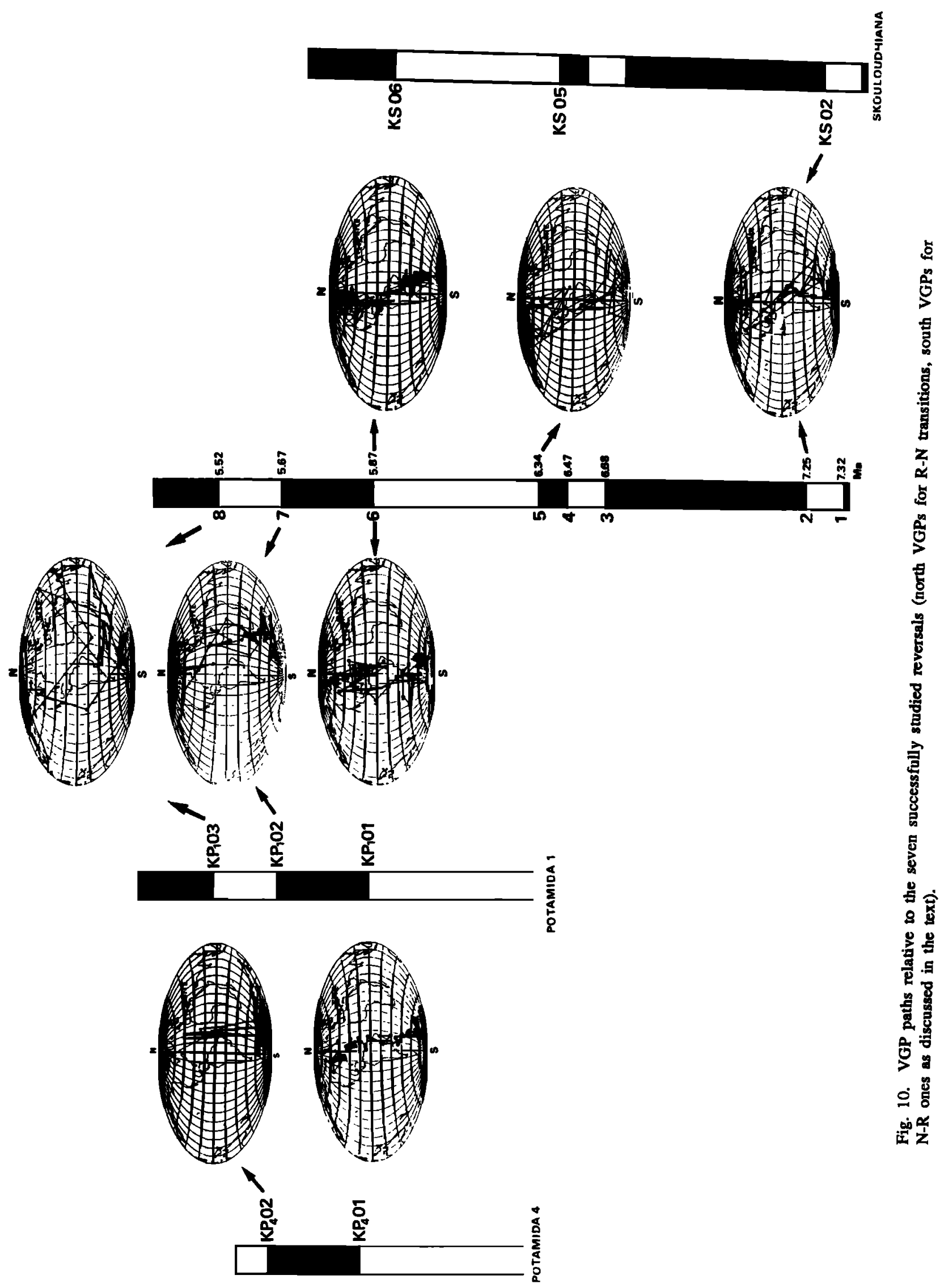



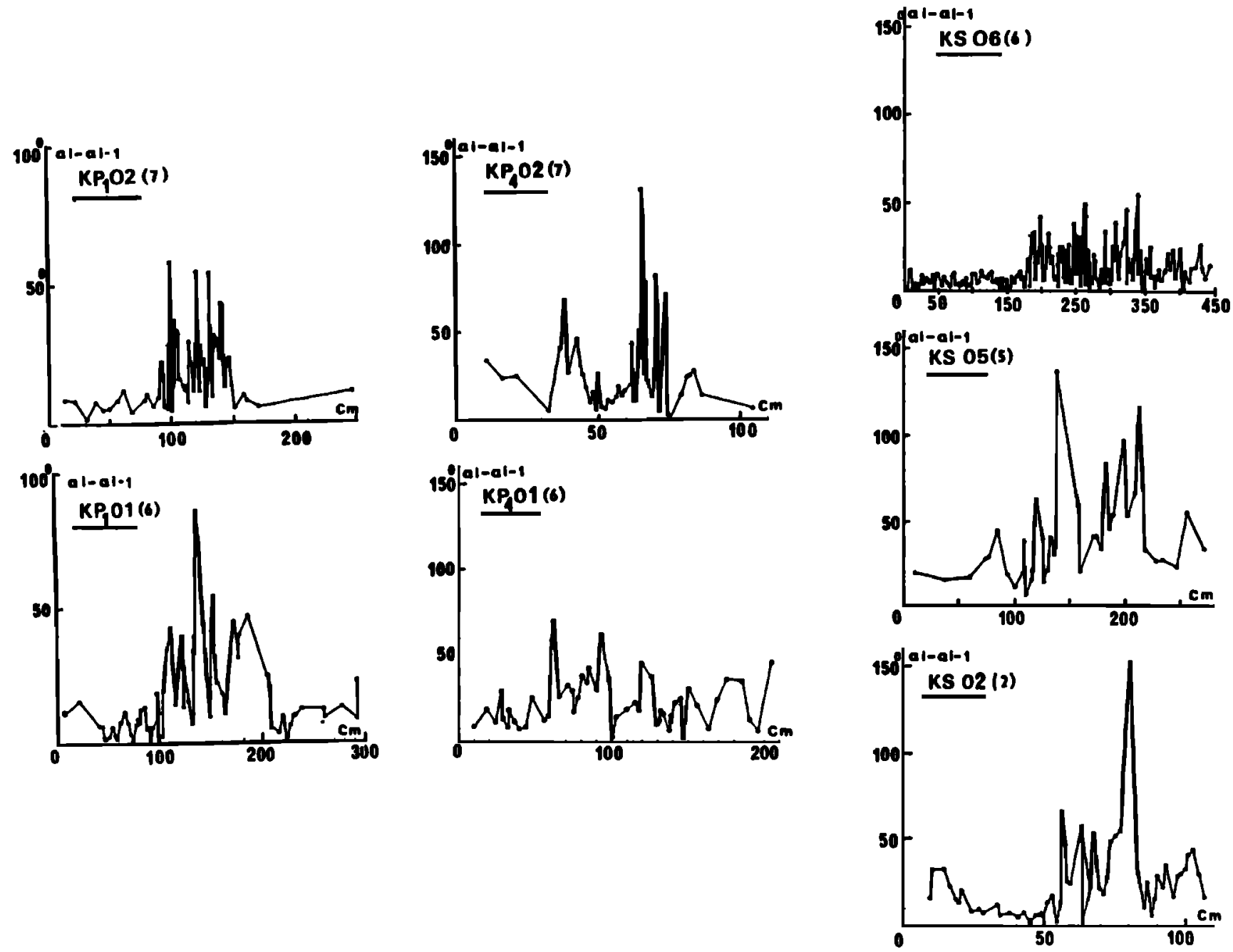

Fig. 11. Plots of the angular changes $\Delta \alpha$ between two successive vectors as a function of stratigraphic height in the transition zones. The systematic increase of the amplitude of $\Delta \alpha$ associated with the transitional directions is probably related to an increased turbulence in the core.

fluctuations were a mere result of a poor magnetic cleaning of an overprint acquired in a nontransitional field, one would expect the vector differences between the paleomagnetic directions of successive samples to be predominantly aligned with the local dipole field (normal or reverse). It has been shown that this is not the case [Valet et al., 1986]. Therefore we believe that at least a significant part of the fast directional fluctuations of the magnetization in the transitional zones represents rapid fluctuations of the geomagnetic field.

Fluctuations also occur on a considerably longer time scale but are masked by the rapid fluctuations. They are well apparent only after a cubic spline smoothing: the directional variations display a pattern of regular oscillations with identical wavelength suggesting a periodicity of some 1000-2000 years, by comparison with the total duration of the transition (Figure 12).

In addition to their physical significance, which will be discussed below, the occurrence of the fast and slow fluctuations is a rather strong evidence for a very limited smoothing due to any postdepositional process. The analysis of these fluctuations has been done on the record of transition
KS 06, which is characterized by a deposition rate higher than the other reversals, so that one may wonder if it is really representative for all the reversals. However, the results described below show that the main characteristics of this record do not significantly differ from the others, so that we are confident that the Cretan clays are quite well adapted for this kind of study.

\section{Directional Characteristics of the Records}

Although the VGP trajectories are largely constrained within rather narrow longitudinal bands, an east to west migration of the VGPs is clearly apparent on most of them and also observed on the stereo plots of $D^{\prime}, I^{\prime}$. To establish whether this trend originates from a real characteristic of the transition field or from particular properties of the sections, we have plotted VGP longitudes as a function of latitude for the different records available of transitions 6 and 7. The results, reported in Figure 13, show that the regression lines have a significantly different slope for the two records of transition 6 at Skouloudhiana and at Potamida 4, while they 


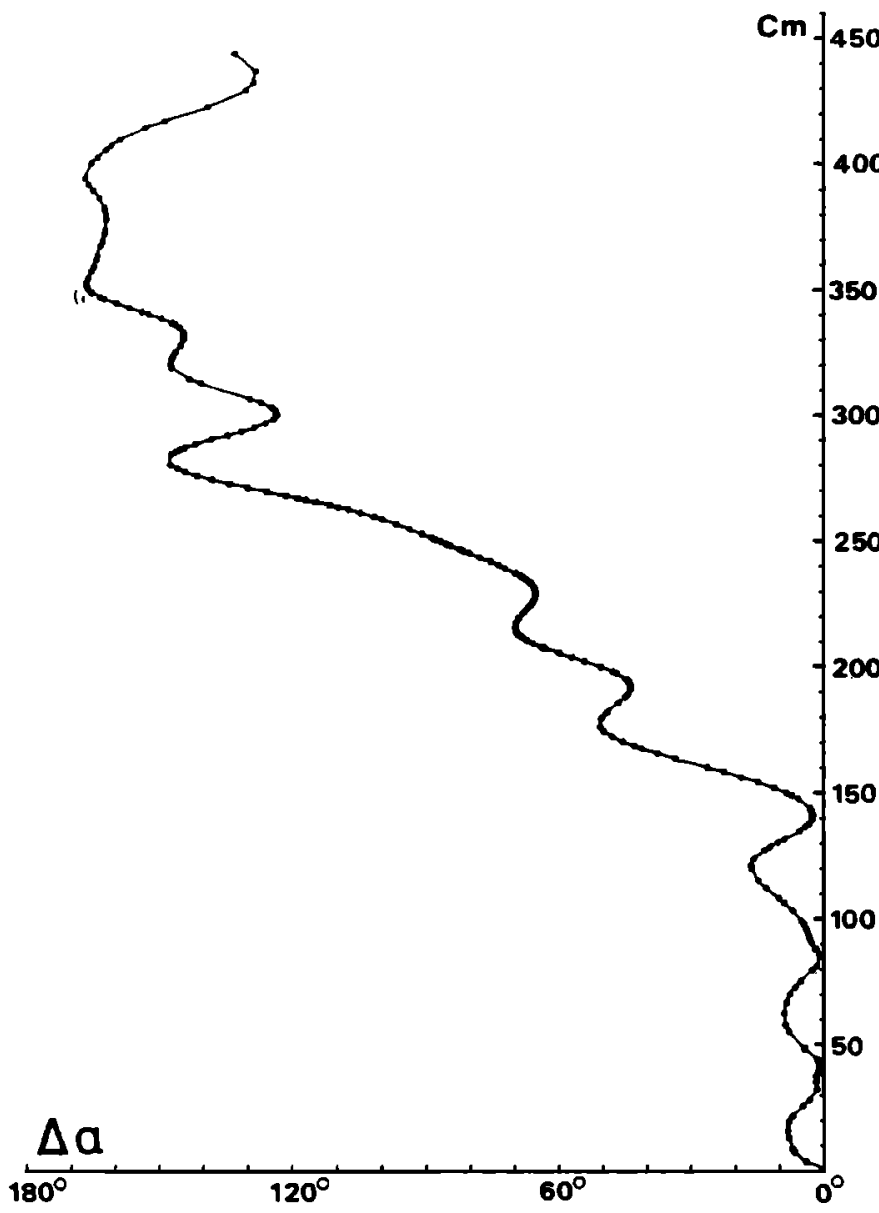

Fig. 12. Angular deviations from the pre-reversal direction relative to the record of reversal 6 at Skouloudhiana. Regular oscillations with identical wavelengths are present before and persist during the transition.

are similar for the two records of transition 7 in the two Potamida sections (Table 2). The results are thus somewhat confusing and probably indicate that in addition to characteristics of the geomagnetic field, several other factors related to the sections may generate the east-to-west trend, although we have no definite idea on the nature of such factors.

The VGP positions (and the rotated directions) associated with KP1 03 are highly scattered in longitude and latitude. Such characteristics are thought to be due to the presence of authigenic minerals in this transition interval, so that any interpretation of this scatter in terms of fluctuations of the geomagnetic field would be highly questionable. For this reason this record will not be further discussed.

The precision obtained on the directional changes was tested by comparing the mean longitudes of the VGP paths associated with the different records of the same reversal. Because a linear relation exists between the VGP longitudes and latitudes (Figure 13), the VGP paths could also be compared from the longitude of their equatorial crossing point. Both methods yielded the same results, summarized in Table 2. The three distinct paths of transition 6 differ by about $15^{\circ}$, while the VGP paths of transition 7 are defined within $20^{\circ}$. On the basis of these values we can distinguish real differences in the VGP paths configuration from eventual distortions between results obtained from distinct sections.

\section{Relative Changes of Field Intensity During the Reversals}

Experimental data. It is well known that the depositional remanent magnetization (DRM) of sediments is related to both the field intensity and the content of magnetic particles, so that simple plots such as those of Figure 7 cannot be interpreted in terms of changes of the intensity of the geomagnetic field. Only in the most favorable cases can a reliable plot of relative intensity be obtained, after normalizing the magnetization to the fraction of magnetic grains carrying the DRM. Noting that the af demagnetization characteristics of DRM and ARM are very similar in magnetite carrying lake sediments, Levi and Banerjee [1976] assumed that the physical cause was that grains of similar size were involved in both DRM and ARM. They then suggested that ARM could be used as a suitable normalizing factor for recovering relative paleointensity changes, similar

TABLE 2. Characteristics of the Linear Regression Lines for the VGP-Longinde Versus Latitude Plots Obtrined for the Three Different Reconds of Transitions 6 and 7

\begin{tabular}{llllccc}
\hline Transition & Site & $\begin{array}{l}\text { Correlation } \\
\text { Coefficient }\end{array}$ & Slope & $\begin{array}{c}\text { Longitude } \\
\text { VGP/Equator }\end{array}$ & Mean Longitude & s \\
\hline R-N 06 & KP4 01 & 0.2 & 0.1 & 296.5 & 297.1 & 22.5 \\
& KP1 01 & 0.8 & 0.3 & 312.4 & 309.8 & 14.3 \\
& KS 06 & 0.9 & 0.6 & 300.8 & 304.0 & 25.0 \\
N-R 07 & KP1 02 & 0.7 & 0.5 & 171.3 & 175.5 & 24.9 \\
& KP4 02 & 0.7 & 0.45 & 152.7 & 151.7 & 30.0 \\
\hline
\end{tabular}

Column 4 gives the longitude of the VGP path at the equator; column 5 gives the average longitude over the entire path with its associated standard deviation. The large longitudinal confinement of the paths is expressed by the low value of the standard deviation. 

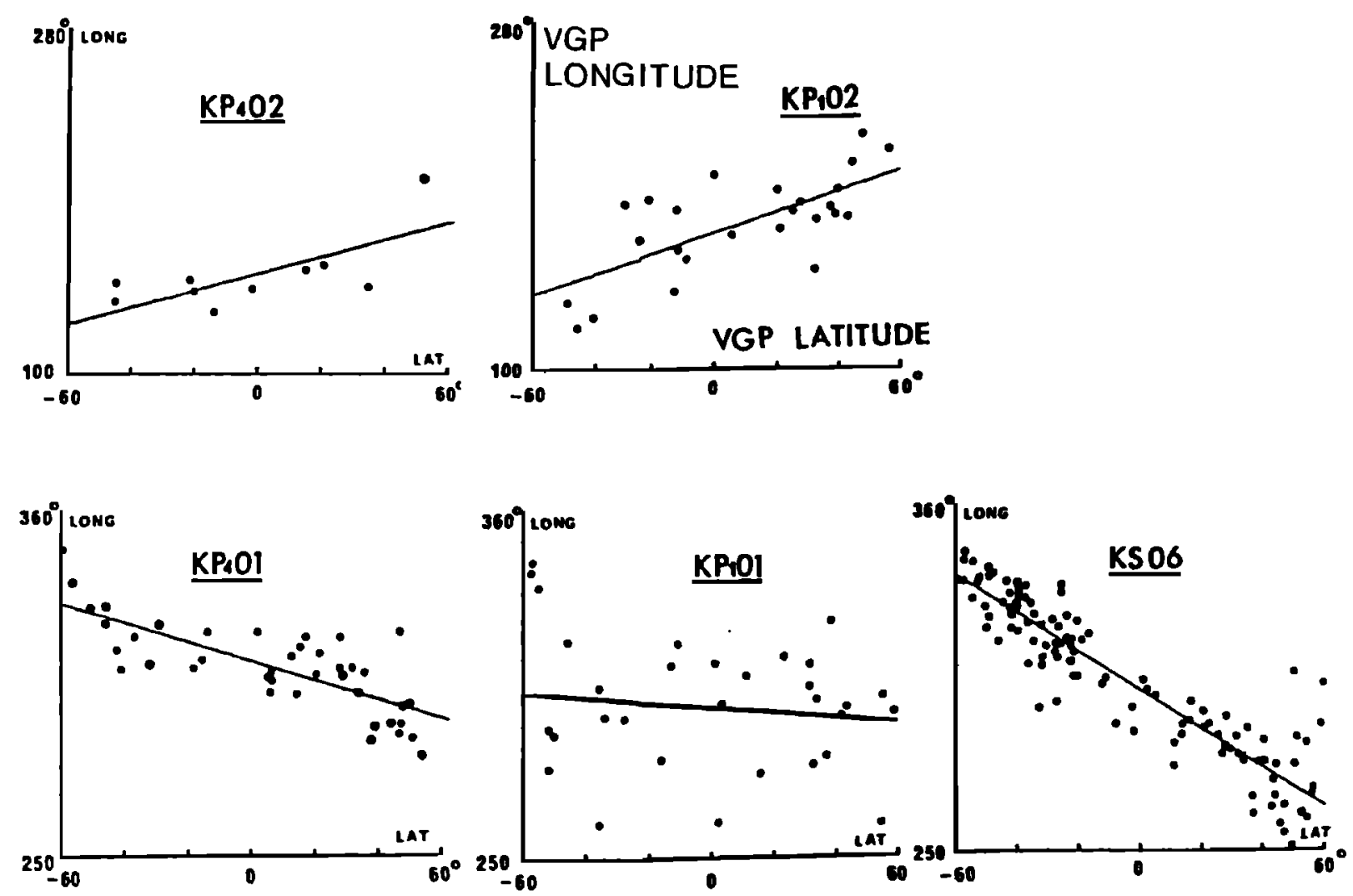

Fig. 13. Longitude versus latitude plots of the VGP positions associated with the different records of transitions 6 and 7 . The slopes of the regression lines are not identical, showing that the east-to-west trend observed in some of the VGP paths is at least partially due to some (unknown) characteristic of the sections.

to what had been done by Johnson et al. [1975]. More recently, King et al. [1983] developed a systematic rock magnetic approach and showed that very reliable relative paleointensity estimates can be obtained from sediments if two basic requirements are fulfilled: first, the magnetic mineral must be magnetite with particle size between 1 and $15 \mu \mathrm{m}$, to retain both a relatively constant DRM/ARM ratio and a stable remanent magnetization [Dankers, 1968; Ozdemir and Banerjee, 1982]; second, the changes of magnetite concentration among samples to be compared must not exceed a factor of $\mathbf{2 0}$ or $\mathbf{3 0}$.

We have followed this approach in the investigation of the sediment from the KS 02, KS 05, KP4 01 and KP1 02 transition zones. As discussed above, magnetite is the dominant magnetic oxyde at Potamida and Skouloudhiana. Considering the grain size, the $\chi(\mathrm{ARM}) / \chi$ plots show that the mean size of the grains is about $0.1 \mathrm{~mm}$ at transitions KP4 01 and KP1 02, lower than the limit given by King et al. [1983]. Yet the points on the plots reported in Figure 6 are remarkably distributed along a single, well-defined line, so that no significant changes in the DRM/ARM ratio seem to have been caused by the small size of the grains. Moreover, the overall good stability of the remanence has been established for both transitions. For the other transitions the grain size is well within the range considered by King et al. [1983]. In the upper part of the KS 02 transition zone the $\chi$ (ARM) $/ \chi$ plots indicate coarser grains, as had already been previously observed from the $\chi / S I R M$ plots. Consequently, in this interval the interpretation of the paleointensity results is more delicate.

We have also checked that the DRM and the ARM demagnetization characteristics are similar. For this test we have used thermal demagnetization because it gives more consistent results. Thus all the experiments were not done on single specimens, as in the case of af demagnetization [Levi and Banerjee, 1976; Johnson et al. 1975] but on pairs of identical samples from exactly the same stratigraphical level, one bearing NRM the other ARM. The normalized demagnetization diagrams, which were compared for temperatures higher than $200^{\circ} \mathrm{C}$ to avoid complications arising from the secondary components of NRM, are very similar (Figure 14) and their ratio close to unity $( \pm 0.1)$; within the limits of this test, ARM and DRM are carried by the same grains. Identical conclusions are reached when different peak values (up to $100 \mathrm{mT}$ ) of the alternating field are used for imposing the ARM, so that any af peak value can be used. Over any sampled interval the amount of magnetite does not change more than a factor of 2 or 3, largely below the maximum limit determined by King et al. [1983]. Yet, in spite of these limited changes, a significant decrease of the ARM is observed at the transitional levels KS 02 and KP1 02. An even more pronounced drop in the ARM has already been reported for KP1 01 [Valet and Laj , 1981], and was interpreted by Kirschvink [1982] and Chang and Kirschvink [1985] in terms of a drop in the population of magnetotactic bacteria during the period of reduced field intensity 

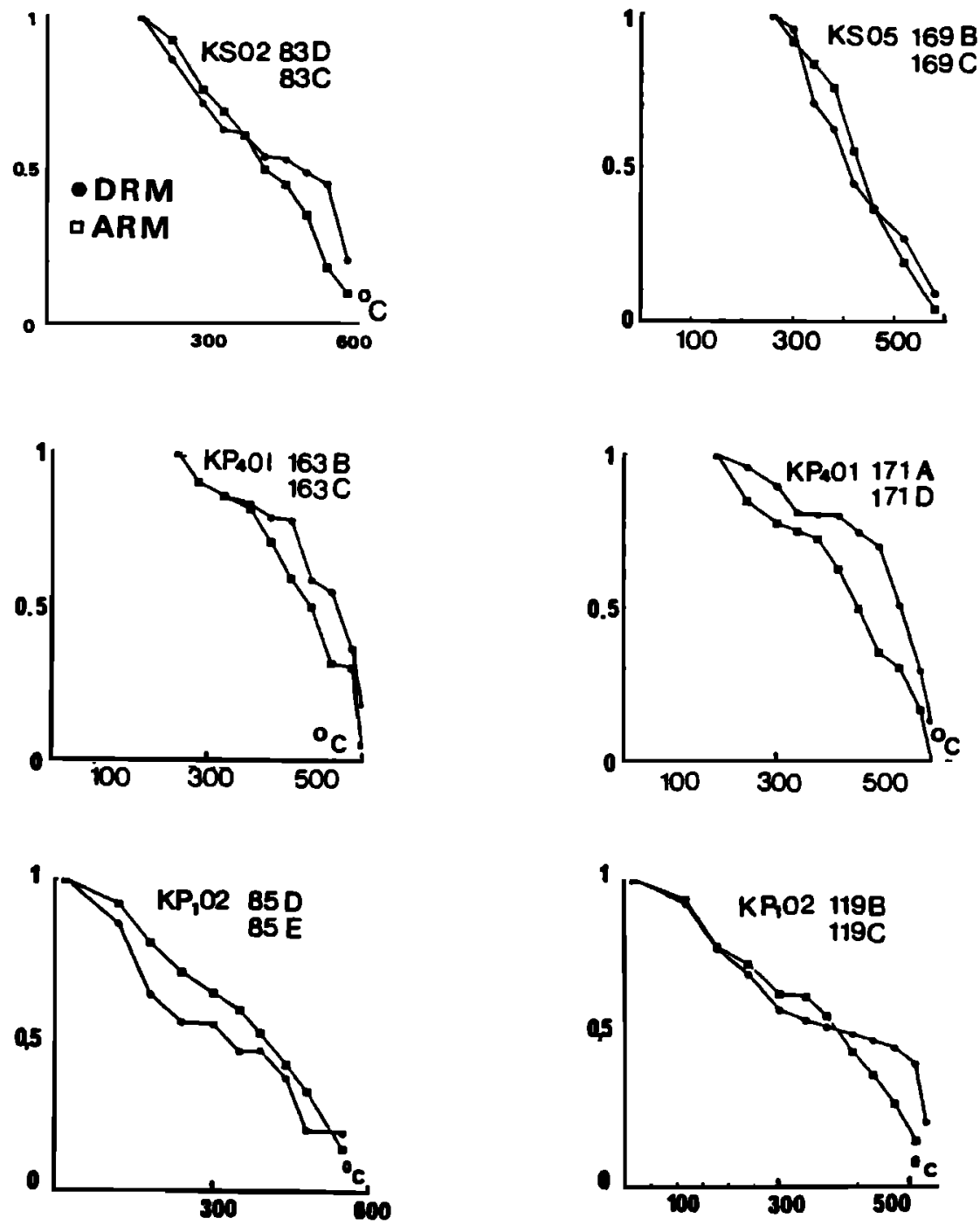

Fig. 14. Variations of the normalized intensity of DRMs and ARMs during thermal demagnetization of "twin" samples from the same stratigraphic levels. Points below $200^{\circ} \mathrm{C}$ have not been considered to avoid complications linked to the secondary components. The demagnetization curves are very similar, indicating that identical grain size populations are involved in both types of magnetization.

corresponding to the reversal. However, no decrease of ARM is observed at KP4 01 (Figure 14), the adjacent record of the same transition from Potamida 4. It seems thus more likely that these variations result at least partially from local, and still not understood, conditions and are not uniquely and directly connected to the geomagnetic field intensity. Summarizing, the coherent and internally consistent results obtained indicate that the sampled clays meet the conditions for a reliable study of the relative changes of the field intensity during the reversals recorded in the Cretan sequences.

Results. The results obtained are shown in Figure 15 , where we report the variations of $\mathrm{DRM}\left(300^{\circ} \mathrm{C}\right) / \mathrm{ARM}(0.05$ $\mathrm{mT}, 80 \mathrm{mT}$ af) as a function of the stratigraphic height obtained for the four reversals. It can be noted that any of the ratios $\operatorname{DRM}\left(300^{\circ} \mathrm{C}\right) / \mathrm{ARM}\left(300^{\circ} \mathrm{C}\right)$ or $\operatorname{DRM}\left(300^{\circ} \mathrm{C}\right) / \mathrm{ARM}$ could equally have been used as a measure of relative field intensity because they are all proportional to each other. The final accuracy can be estimated by comparing the results of the two distinct records of transition 6 at Potamida 4 and Potamida 1 [Valet and Laj, 1981]: the field intensity was reduced to $35 \%$ of its original value when the KP4 01 record is considered and to $20 \%$ according to the one of KP1 01 (this difference may be somewhat exagerated because the whole field variations are probably not entirely recovered in KP4 01).

The curves of Figure 15 represent our best approximation, to about $20 \%$, for the relative variations of the geomagnetic field intensity during the four reversals. Within this limit, these results indicate the following:

There is a significant and systematic decrease of field intensity during every reversal studied.

The field intensity was reduced to $10-25 \%$ of its 

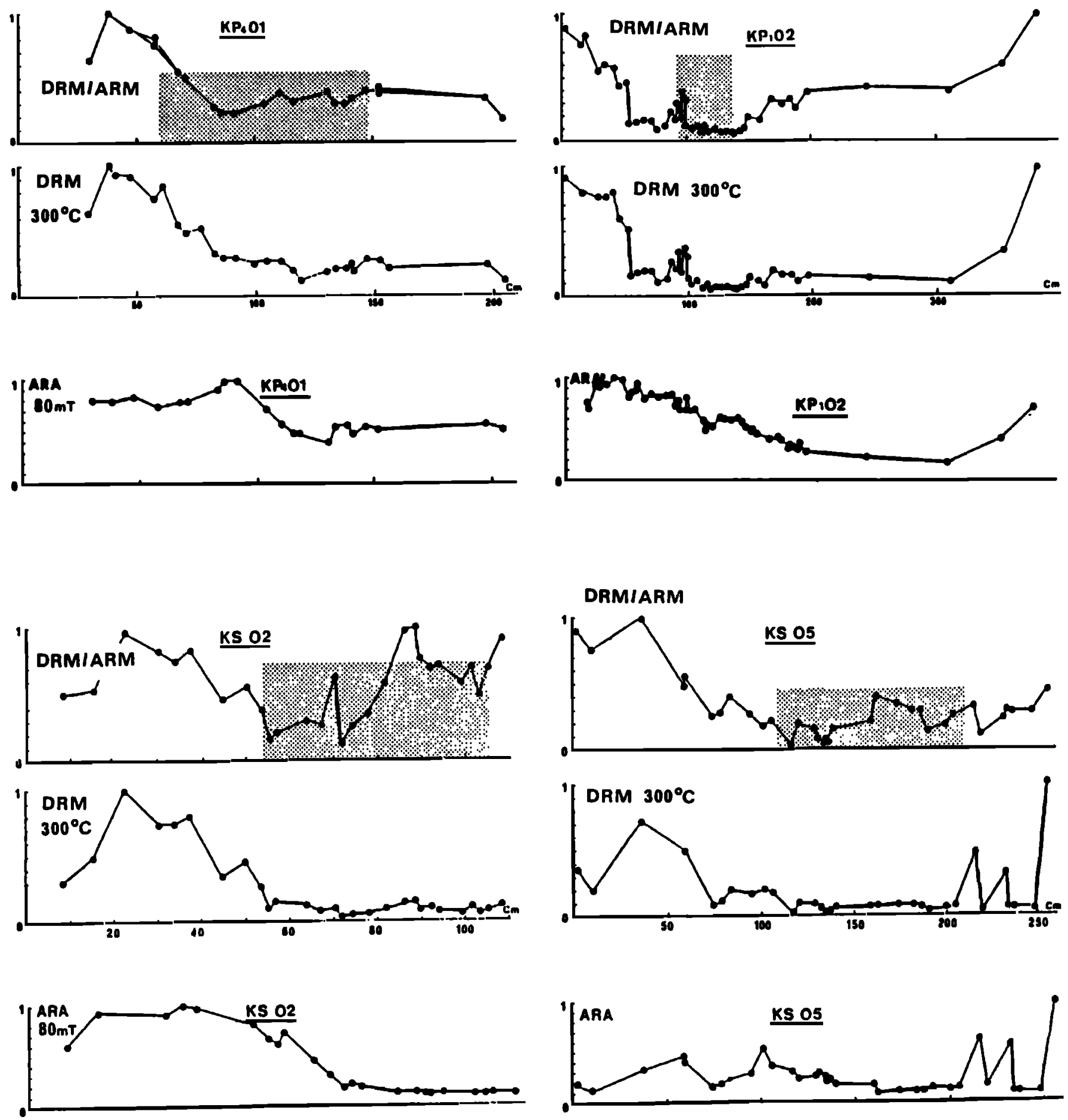

Fig. 15. Variations of the ARM(0.05 $\mathrm{mT} ; 80 \mathrm{mT})$, DRM after $300^{\circ} \mathrm{C}$, and of the ratio $\mathrm{DRM}\left(300^{\circ} \mathrm{C}\right) / \mathrm{ARM}$ as a function of stratigraphic height for transitions $2,5,6$, and 7 . The DRM $\left(300^{\circ} \mathrm{C}\right) / A R M$ ratios are our best approximation of the relative variations of the geomagnetic field during the four reversals, to about $20 \%$. In all the cases there is a significant decrease of the field intensity associated with the directional changes (indicated by the hatchured zones).

pretransitional value, an order of magnitude commonly reported either by absolute paleointensities studies from volcanic rocks [Bogue and Coe, 1984; Prévot et al., 1985 a,b] or by sedimentary records [Hoffman, 1983; Jacobs, 1984].

There was no evidence for intermediate transitional stages associated with high intensities. The intensity drop seems to have occurred on a time scale at least twice as long as the directional changes.

The sequences of directional changes associated with transitions of opposite sense can be compared directly by examining the plots of either the rotated directions or the VGPs reported in Figures 9 and 10. It can be seen from 
TABLE 3. Values of the Ratio $R=\pi /\left(X^{2}+Y^{2}\right)^{1 / 2}$ Calculnted for Reversals $2,5,6$, and 7

\begin{tabular}{ccccc}
\hline \multicolumn{5}{c}{ Transition } \\
\cline { 2 - 4 } & 5 & 6 & 7 \\
\hline & $1.22 \pm 0.91(\mathrm{KSO2})$ & $1.00 \pm 0.8(\mathrm{KSOS})$ & $1.26 \pm 0.9(\mathrm{KSO6})$ & $0.27 \pm 0.1(\mathrm{KPO})$ \\
& & $0.98 \pm 0.8(\mathrm{KP101})$ & $0.40 \pm 0.3(\mathrm{KP402})$ \\
& & & $1.05 \pm 0.5(\mathrm{KP401})$ &
\end{tabular}

The comparable amplitude of east-west and north-wouth fluctuations in transitions 2, 5, and 6 is expresssed by the $R$ values close to unity, while the low value obtained for transition 7 indicates a larger influence of axisymetric terms.

Figures 9 and 10, that within the acccuracy discussed above, the directions (or equivalently the VGP paths) associated with the R-N transitions 2 and 6 and the N-R transition 5 are identical and differ significantly from the intermediate directions of transition 7. This main result, previously reported elsewhere [Valet and Laj, 1984] and now confirmed by the additional records KP4 01 and KP4 02 from Potamida 4 , indicates that the process of reversal from either starting polarity remained unchanged over the time interval of at least 1.3 m.y., corresponding to the first three reversals. A change then occurred for the next reversal. As discussed above, the bad magnetic properties of the sediment corresponding to transition 8 (i.e., the ferrigineous level IV) has hindered any precise study of this transition, so that it has not been possible to distinguish whether this change in the reversal process marks the beginning of a new period of invariance or the end of an exceptional period of invariance. In this respect it must indeed be noted that the long time persistence of the reversal process observed in Crete has not been observed in the only other study of sequences of reversals, the Olduvai and Jaramillo reversals, which has been published [Herrero-Bervera and Theyer, 1986]. On the contrary, in the latter, different transitional characteristics have been observed for each transition.

When discussed in terms of published phenomenological models, the Cretan records are clearly inconsistent with the "standing field" model but instead can be described in terms of "generalized flooding field" models [Hoffman, 1981]. In contrast with our results, the attempt at zonal harmonic modeling of the upper Olduvai and lower Jaramillo transitions obtained from a southem hemisphere deep-sea sediment [Clement and Kent, 1985] is consistent with the idea of a standing field which persisted across the two reversals. However, as Clement and Kent [1985] stated, this interpretation is poorly constrained by the lack of a broad geographic distribution of these transitions. This requirement is corroborated by the fact that the two particular solutions obtained from the fit of the northem hemisphere [Theyer et al., 1985] and southern hemisphere [Clement and Kent, 1985] inclination data of the lower Jaramillo transition using the Williams and Fuller's [1981] approach are clearly incompatible.

Because no other record of the reversals studied here is available from other geographical areas, it is not possible to obtain any quantitative or even qualitative description of the harmonic terms controlling the "flooding" tield during the transition. However, the globally smooth appearance of the paths and the longitudinal confinement suggest a "simple" structure of the transitional field, probably dominated by low-order harmonics. It is also clear that nonaxisymmetrical terms are present, as evidenced by the fact that the VGP paths are situated roughly $90^{\circ}$ away from the site longitude, west or east depending on the sense of the transition, or equivalently by the fact that the rotated directions lie in the plane containing the horizontal east-west line and the axial dipole field direction. Prévot et al. [1985 a] have shown that a good estimate of the relative amplitude of nonaxial to axial terms is given by the parameter $R=/ Y I\left(X^{2}+Y^{2}\right) 1 / 2$, where $/ X /$ and $/ Y I$ are the root mean square values of the north-south and east-west components respectively of the field during the transitions. For transitions 2,5, and 6 the mean values of $R$, summarized in Table 3, range between 1 and 1.2, indicating that the nonaxisymmetric terms are about as large as the axisymmetric ones. Sectorial or tesseral spherical harmonics are required to account for these significant deviations from the north-south axis. Most of the detailed published records of reversals obtained either from volcanic or sedimentary sequences [Hoffman, 1985; Valet, 1985; Bogue and Coe, 1984; Hillhouse and Cox, 1976; Prévot et al.,1985 a,b] show evidence that non-axisymmetric components play a major role in the description of the transitional field.

In contrast with the other transitions, the rotated directions $D^{\prime}, I^{\prime}$ of reversal 7 lie only about $20^{\circ} .40^{\circ}$ away from the north-south axis and the VGP path lies $20^{\circ}-30^{\circ}$ away from the antipodal site meridian. The values of $R$ between 0.2 and 0.4 confirm that during this transition, the field was significantly dominated by zonal components.

Another basic characteristic of the reversal process, clearly shown by the Cretan records, is the large increase of the amplitude of the directional fluctuations during the reversals. Such fluctuations are present in many sedimentary records but have not, in general, received much consideration. In certain cases, it has even been implicity assumed that they represent an overall random noise. Prévot et al. [1985 a,b ] suggested that the large directional jumps observed in the record of the Steens Mountain reversal could reflect an increase in the level of the turbulence within the Earth's liquid core under frozen flux constraints during the reversal. The overall presence of short-term directional variations during the Cretan reversals as well as in most palaeomagnetic records suggests that a higher turbulence level in the core would be systematically associated with the processes governing reversals.

The hypothesis that frozen flux dominated processes play a role in the reversal is also supported by the analysis of the 


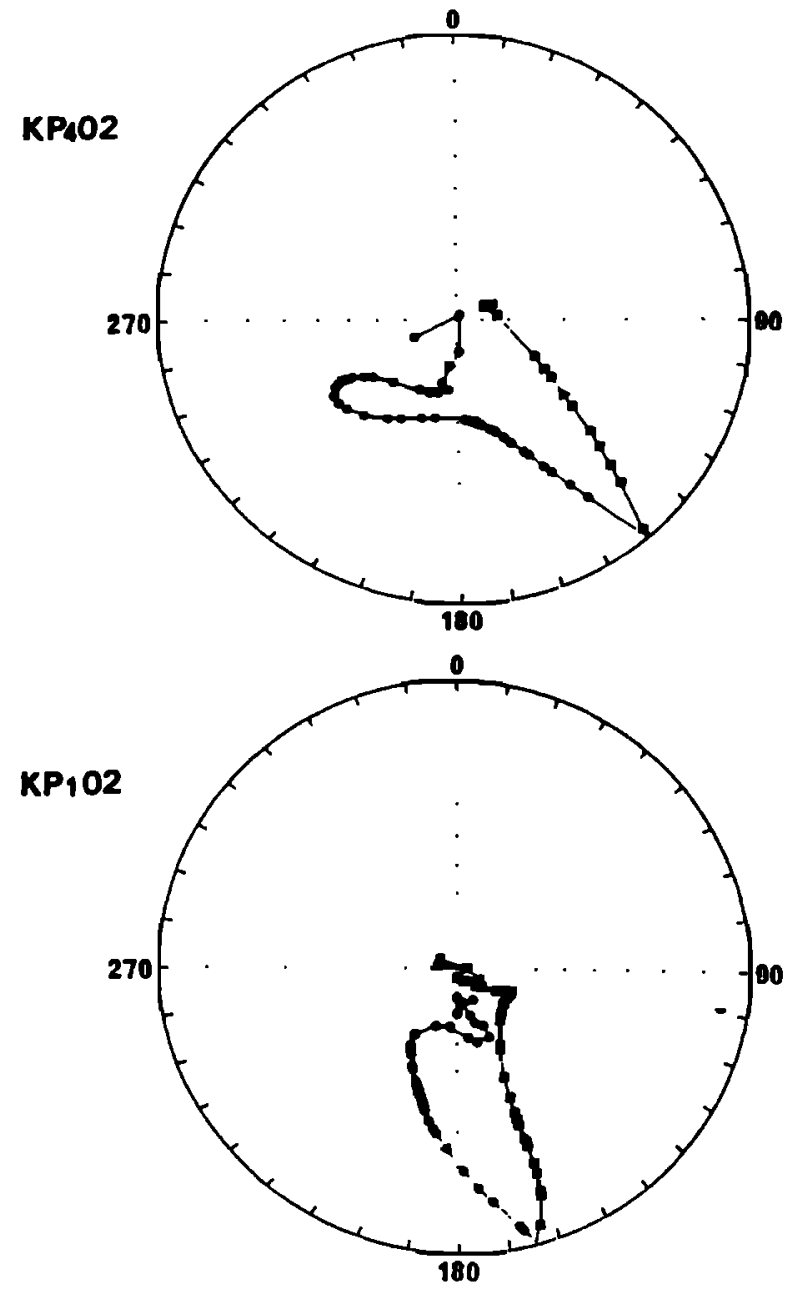

Fig. 16. Polar stereographic projection of the rotated directions $D^{\prime}, I^{\prime}$ (after a shight smoothing) for the two records of transition 7 at Potamida 1 and 4 showing the existence of a disturbance at the onset of the reversal (more marked on the KP4 02 record).

long-term fluctuations shown in Figure 12. It can be seen that three oscillations occur before the onset of the transition and that their apparent periodicity persists during the transition. This suggests that part of the nondipolar geomagnetic field is not affected by the polarity change. When interpreted in terms of recent theoretical results [Le Mouell, 1984], this observation also suggests that the frozen flux approximation might be valid for time spans of the order of a thousand years.

Finally, it can be seen on the stereo plots of Figure 16 obtained after a slight cubic spline smoothing of the data that transition 7 was preceded by a large loop with intermediate directions lying close to the east-west axis. In transition KS 06 a significant excursion occurred on the contrary at the very end (Figure 12). These two perturbations at the onset of the reversal for transition 7 and at the end for transition 6 may be related to a recent mechanism for reversal suggested by McFadden and Merrill [1986]. McFadden and Merrill have proposed that reversals arise when occasional disturbances perturb the main movement in the core in a way somewhat similar to that suggested by Olson [1983]. When the perturbation originates at the core-mantle boundary and sinks into the core ("cold blob" in the Olson's terminology), it will affect the outer core first, so it should perturb the secular variation at the onset of the reversal. When, on the contrary, a perturbation is generated at the solid core-liquid core boundary ("hot blob") possible perturbations would be expected at the end of the transition. McFadden and Merrill also suggest, on the basis of published records, that the "cold blob" mechanism is to be preferred.

The data relative to the Cretan reversals are not all sufficiently precise to verify that perturbations are present in all cases either at the onset or at the end of the reversals and so cannot prove the reality of the mechanism suggested by McFadden and Merrill. However, the characteristics observed for transitions 6 and 7 suggest that if the mechanism is true, then both the "hot blob" and "cold blob" triggering processes might occurr. Clearly, additional studies of sequential reversals are needed to establish the reality and eventually the frequency of such changes of the mechanism for triggering reversals.

Acknowledgments. Discussions with V. Courtillot, M. Prévot, and H. Zijderveld were most helpful. C. Kissel, S. Sen, and M. Villegier helped with the sampling. The microprobe analyses were supplied by $C$. Jehanno; the thermomagnetic measurements were supplied by P. Roperch. We thank L. Tauxe, S. Lund, and an anonimous reviewer for providing very helpful and thorough criticisms of the original manuscript. The Director of the IGME in Athens kindly provided the necessary permits. The financial support was given by the Commissariat à l'Energie Atomique, the Centre National de la Recherche Scientifique and by the Action Thématique Programmée "Noyau" of the Institut National des Sciences de l'Univers. We are very indebted to all the people of the village of Dermitziana. The Papadakis Hotel and the Papadakis restaurant in Kastelli are highly recommended for future developments of the study of upper Miocene reversals of the geomagnetic field. This is Centre des Faibles Radioactivités contribution 878 .

\section{References}

Banerjee, K., J. King, and S. Marvin, A rapid method for magnetic granulometry with applications to environmental studies, Geophvs. Res. Lett. _ 8, 333-336, 1981.

Bogue, S.W., and R.S. Coe, Transitional paleointensities from Kauai, Hawai, and geomagnetic reversal models, $L$ Geophys. Res. 89 10,341-10,354, 1984.

Chang, S.R., and J. L. Kirschvink, Possible biogenic magnetite fossils from the Miocene Potamida clay of Crete in Mapnetic Biomineralization and Magnetoreception in Organisms edited by J.-L., Kirschvink, D.S. Jones, and B.J. MacFadden , Plenum Press, New York and London, 1985.

Chiron, G., C. Laj and J. Pocachard, A high sensitivity portable spinner magnetometer, LPhys. E. L4 977-981, 1981.

Clement, B.M., and D.V. Kent, A detailed record of the lower Jaramillo polarity transition from a southern hemisphere deep-sea sediment core, L.Geophys. Res. 89, 1049-1058. 1984. 
Clement, B.M., and D.V. Kent, A comparison of two sequential geomagnetic polarity transitions (upper Olduvai and lower Jaramillo) from the southern hemisphere, Ehvs. Earth Planet. Inter. 39 301-313, 1985.

Dankers, P.H.M., Magnetic properties of dispersed natural iron-oxydes of known grain size. Ph.D. thesis, Univ. of Utrecht, Netherlands, 1968.

Drooger, C.W., J.E. Meulenkamp, C.G. Langereis, A.A.H Wonders, G.J. Van der Swoen, M.M. Drooger, D.S.N. Raju, P.H. Doeven, W.J. Zachariasse, R.R. Schmidt, and J.D.A. Zijderveld, Problems of detailed biostratigraphic and magnetostratigraphic correlation in the Potamida and Apostoli sections of the cretan Neogene, Utrecht Micropaleontol. Bull. 21, 1-222, 1979.

Fuller, M., I. Williams, K.A. Hoffman, Paleomagnetic records of geomagnetic reversals and the morphology of the transitional field, Rev Geophys. I7 172-203, 1979.

Herrero-Bervera, E., and F. Theyer, Non axisymetric behaviour of Olduvai and Jaramillo polarity transitions recorded in north-central Pacific deep-sea sediments, Nature. 322. 159-162, 1986.

Hillhouse, J., and A. Cox, Brunhes-Matuyama polarity transition , Earth Planet. Sci. Lett. 29, 51-64, 1976.

Hoffman, K.A., Quantitative description of the geomagnetic field during the Matuyama-Brunhes polarity transition, Phys. Earth Planet. Inter.. 24.229-235, 1981.

Hoffman, K.A., Geomagnetic reversals and excursions: Their paleomagnetic record and implications for the geodynamo, Rev. Geophys. $2 L$ 614-620, 1983.

Hoffman, K.A., A method for the display and analysis of transitional paleomagnetic data, $L$ Geophys. Res.. 89. $6,285-6,292,1984$.

Hoffman, K.A., Transitional behaviour of the geomagnetic field, J. Geomapn. Geoelectr. 37, 139-146, 1985.

Hoffman, K.A., and B.S. Slade, Polarity transition records and the acquisition of remanence: A cautionary note, Geophys. Res. Lett.. 13. 483-486, 1986.

Irving, E. and A. Major, Post-depositional remanent magnetization in a synthetic sediment, Sedimentology. 3 . 135-143, 1964

Jacobs, J.A., Reversals of the Earth's Magnetic Field 230pp Hilger, Bristol , 1984.

Johnson, H.P., H. Kinoshita, and R.T. Merrill, Rock magnetism and paleomagnetism of some North Pacific deep-sea sediment cores, Geol. Soc. Am. Bull. 86, 412-420, 1975.

Katsura, I., and S. Sasajima, Note on the experimental acquisition of remanence in sediment during a field reversal, Mem. Fac Sai.Kyoto Univ. Ser. Geol Mineral 67-74, 1983.

King, R.F., The remanent magnetism of artificially deposited sediments, Mon. Not. R. Astron. Soc. Geophys. Suppl. 7. 115,1955

King, J.W., S.K. Banerjee, J. Marvin and O. Ozdemir, A comparison of different magnetic methods for determining the relative grain size of magnetite in natural materials: Some results for lake sediments, Earth Planet. Sci. Letl. 59 404-419, 1982.

King, J. W., S.K. Banerjee and J. Marvin, A new rock magnetic approach to selecting sediments for geomagnetic paleointensity studies: Application to paleointensity for the last 4000 years, L. Geophys. Res. 88. 5911-5921, 1983.

Kirschvink, J.L., Palaeomagnetic evidence for fossil biogenic magnetite in western Crete, Earth Planet. Sci. Leth. 59 388-392, 1982.
Laj, C., M. Jamet, D. Sorel, and J.-P. Valente, First palcomagnetic results from Mio-Pliocene series of the hellenic sedimentary arc, Tectonophysics. 86, 45-67, 1982.

Langereis, C.G., Late Miocene magnetostratigraphy in the Mediterranean, Ph.D. thesis,195 pp, State Univ. of Utrecht, Utrecht, Netherlands, 1984.

Langereis C.G., Zachariasse W.J. and Zijderveld J.D.A., Late Miocene magnetostratigraphy of Crete, Mar. Micropaleontol. 8. 261-281, 1983/84.

Le Mouel, J.L., Outer-core geostrophic flow and secular variation of earth's geomagnetic field, Nature 311 . 734-735, 1984.

Levi, S., and S.K. Banerjee, On the possibility of obtaining relative paleointensities from lake sediments, Earth Planet Sci._ett. 29, 219-226, 1976.

Lovlie, $R$., The intensity pattern of post-depositional remanence acquired in some marine sediments deposited during a reversal of the external magnetic field, Earth Planet. Sai.Lett. 30. 209-214, 1976.

Lowrie, W., and W. Alvarez, One hundred million years of geomagnetic polarity history, Geology \& 392-397, 1982.

Lowrie, W., and F. Heller, Magnetic properties of marine limestones, Rev. Geophys..20, 171-192 _ 1982.

MacFadden, P.L., and R.T. Merrill, Geodynamo energy source constraints from paleomagnetic data, Ehys. Earth Planet. Inter. 43, 22-33, 1986.

Olson, P., Geomagnetic polarity reversals in a turbulent core, Bhys. Earth Planet. Inter. 33.260-274, 1983.

Ozdemir, O., and S.K. Banerjee, A preliminary study of soil evolution in west central Minnesota, Earth Planel. Sci. Lett. 59, 393-403, 1982.

Prévot, M., E.A. Mankinen, C.S. Gromme, and R.S. Coe, The Steens Mountain polarity transition, 2, Field intensity variations and discussion of reversal models, L Geophys. Res. 90 10,417-10,448, 1985 a.

Prévot, M., F.A. Mankinen, C.S. Gromme, and R.S. Coe How the geomagnetic field vector reverses polarity, Nature 316 230-234, $1985 b$.

Salloway, J.C. . The structure of the geomagnetic field during polarity transitions and excursions, Ph.D. thesis, 296 PP, Univ. of Edinburgh , Edinburgh, Scotland, 1983.

Theyer, F., E. Herrero-Bervera and V. Hsu, The zonal harmonic model of polarity transitions: A test using successive reversals, L. Geophys, Res, 90_ 1963-1982, 1985.

Tucker, P., Selective post-depositional realignment in a synthetic sediment, Bhys. Earth Planet. Inter. 20, 11-14, 1979.

Tucker, P., A grain mobility model of post-depositional realignment. Geophys. $L$. $R$. Astron. Soc. 63. 149-163, 1980.

Tucker, P., Magnetization of unconsolidated sediments and theories of DRM in Geomagnetism of Backed Clav and Recent Sediments edited by K.M. Creer, P. Tucholka, and C.E. Barton, pp 9-19, Elsevier, Amsterdam, 1983.

Valet, J.-P., Inversions géomagnétiques du Miocène supérieur en Crète. Modalités du renversement et caractéristiques du champ de transition, thèse d'état, 195 pp, Univ. d'Orsay, France, 1985.

Valet, J.-P., and C. Laj, Paleomagnetic record of two successive Miocene geomagnetic reversals in western Crete, Earth Planet. Sci. Lath. 54, 53-63, 1981.

Valet, J.-P., and C. Laj, Invariant and changing transitional field configuration in a sequence of geomagnetic reversals, Nature. 31L 552-555, 1984.

Valet, J.-P., C. Laj, and C.G. Langereis, Two different R-N 
geomagnetic reversals with identical VGP paths recorded at the same site, Nature, 304 330-332, 1983.

Valet, J.-P., C. Laj, and P. Tucholka, High resolution sedimentary record of a geomagnetic reversal, Nature. 322. 27-32, 1986.

Vandenberg. J., Reappraisal of paleomagnetic data from Gargano (South Italy) , Tectonophwsics. 98, 29-41, 1983.

Verosub, K.L., Depositional and post-depositional process in the magnetization of sediments, Rey. Geophys. 15 , 129-143, 1977.

Williams, I., and M. Fuller, Zonal harmonic models of reversal transition fields, $L$ Geophys. Res. 86 11,657-11,665, 1981.

C. Laj and J.P. Valet, Centre des Faibles Radioactivités, Laboratoire mixte CNRS/CEA, Gif-sur-Yvette Cedex 91198, France.

C.G. Langereis, Paleomagnetisch Laboratorium, 'Fort Hoofddijk', Utrecht, Nederlands.

(Received March 30, 1987;

revised October 5, 1987;

accepted October 5, 1987.) 